\title{
Sinomenine prevents metastasis of human osteosarcoma cells via $S$ phase arrest and suppression of tumor-related neovascularization and osteolysis through the CXCR4-STAT3 pathway
}

\author{
TAO XIE ${ }^{1}$, HAI-YONG REN ${ }^{1}$, HAI-QING LIN $^{2}$, JIN-PING MAO ${ }^{1}$, \\ TING ZHU $^{1}$, SHENG-DONG WANG ${ }^{1}$ and ZHAO-MING YE $^{1}$ \\ ${ }^{1}$ Department of Orthopedics, Second Affiliated Hospital, School of Medicine, Zhejiang University, \\ Hangzhou, Zhejiang; ${ }^{2}$ Department of Orthopedics, Second Jiaxing Hospital, Jiaxing, P.R. China
}

Received November 6, 2015; Accepted December 15, 2015

DOI: $10.3892 /$ ijo.2016.3416

\begin{abstract}
Osteosarcoma is the most common primary malignant tumor of the bone. The long-term survivals continue to be unsatisfactory for patients with metastatic and recurrent disease. Metastasis is still a severe challenge in osteosarcoma treatment. Sinomenine, an alkaloid from traditional Chinese medicine, has been proved to possess potent antitumor and anti-invasion effect on various cancers. However, the effect of sinomenine on human osteosarcoma and the underlying mechanisms remains unknown. We report here that sinomenine inhibited proliferation by inducing $S$ phase arrest and suppressing the clone formation. Significant inhibitory effects were found in invasion and metastasis in osteosarcoma, but little cytotoxicity was observed in tested concentrations. Exposure to sinomenine resulted in suppression of invasion and migration in osteosarcoma cells as well as tube formation ability in the human umbilical vein endothelial cells (HUVEC) and $\mathrm{U}_{2} \mathrm{OS}$ cells. Furthermore, it demonstrated that CXCR4 played a key role contributing to invasion in osteosarcoma which is considered to be a core target site in sinomenine treatment. Sinomenine inhibited invasion by suppressing CXCR4 and STAT3 phosphorylation then downregulating the expression of MMP-2, MMP-9, RANKL, VEGF downstream. In addition, then RANKL-mediated bone destruction stimulated by osteoclastogenesis and VEGF-related neovascularization were restrained. Importantly, in vivo, sinomenine suppressed proliferation, osteoclastogenesis and bone destruction. Through these various comprehensive means, sinomenine inhibits metastasis in osteosarcoma. Taken together, our results
\end{abstract}

Correspondence to: Dr Zhao-Ming Ye, Department of Orthopedics, Second Affiliated Hospital, School of Medicine, Zhejiang University, 88 Jiefang Road, Hangzhou, Zhejiang 310009, P.R. China

E-mail: yezhaomingz2@163.com

Key words: sinomenine, osteosarcoma, metastasis, invasion, CXCR4, osteoclastogenesis, neovascularization revealed that sinomenine caused $\mathrm{S}$ phase arrest, inhibited invasion and metastasis via suppressing the CXCR4-STAT3 pathway and then osteoclastogenesis-mediated bone destruction and neovascularization in osteosarcoma. Sinomenine is therefore a promising adjuvant agent for metastasis control in osteosarcoma.

\section{Introduction}

Osteosarcoma is the most common primary malignant bone tumor. It occurs mainly in children and adolescents with a very high tendency for local invasion and early systemic metastases $(1,2)$. Generally, it is considered an aggressive malignancy that arises from mesenchymal origin which exhibits osteoblastic differentiation and produces malignant osteoid matrix (2). The 10-year overall survival rate has improved to $\sim 65 \%$ attributed to neoadjuvant chemotherapy and improved surgical techniques which nevertheless remains essentially unchanged during the past two decades $(3,4)$. However, 10 -year survival rates continue to be unsatisfactory for patients with metastatic and recurrent disease, respectively, 25\% (5) and <20\% (6). Therefore, metastasis is still a severe challenge in osteosarcoma treatment. It is urgent to develop novel treatment options for management of osteosarcoma, especially for control of metastasis and recurrence.

Invasion and metastasis are important biological characteristics of malignant tumors. In progression of tumor invasion and metastasis, the degradation of extracellular matrix (ECM) and the basement membrane, isolation of cells and connective tissues, seem to be the important steps. The matrix metalloproteinase proteins (MMPs) are demonstrated to be involved in degradation of most extracellular matrix. They are overexpressed in malignancies and are considered to be associated with metastasis, invasiveness, migration and angiogenesis (7). The gelatinase, MMP-2 and MMP-9, are the major proteases of all MMPs which contribute to migration and invasion in osteosarcoma pathogenesis. Furthermore, MMP activities are regulated by the tissue inhibitors of metalloproteinases (TIMPs). Imbalance between the expression of MMPs and 
TIMPs is a crucial element involved in the remodeling of the ECM exhibited in the process of cancer invasion and metastasis (8). Therefore, the MMP-2 and MMP-9 are targets for anticancer drugs.

Malignant bone lesions are very common in patients with cancer. Excessive osteogenesis and osteolysis concurrence in osteosarcoma resulting from tumor process. Receptor activator of $\mathrm{NF}-\kappa \mathrm{B}(\mathrm{RANK})$ and its ligand (RANKL) play pivotal roles in the regulation of bone remodelling to maintain bone homeostasis. One of most important inducement of osteolysis in osteosarcoma is overexpression of tumor-related RANKL. The over-activated RANKL stimulates numerous osteoclastogenesis and subsequent bone destruction and resorption (9). Osteosaroma usually occurs in long bone cavities. The bone cortex and periosteum restrain the tumor in cavity mesooecium as a natural isolation. Along with the tumor progress, tumorrelated activation of MMPs and RANKL degrade the ECM and induce further bone cortex destruction, and then the tumor cells invade into the surrounding soft tissues with consequent metastasis.

Sinomenine $\left(\mathrm{C}_{19} \mathrm{H}_{23} \mathrm{NO}_{4}\right.$, Fig. 1A), an alkaloid isolated from the Chinese medicinal herb, has been successfully utilized to treat rheumatoid arthritis for centuries (10). Furthermore, sinomenine has previously been demonstrated to have a wide range of pharmacological effects, including anti-inflammatory effects, immunosuppression, anti-angiogenic as well as analgesic effects. Sinomenine has attracted great attention for its anti-neoplasm potential. It has been demonstrated to inhibit cell proliferation and induce apoptosis in a variety of human tumor cells (11-14). Li et al (15) reported that sinomenine induces vasculature normalization that contributes to antitumor and anti-metastasis effect on breast cancer. In addition, inhibitory effects of sinomenine on cancer invasion and migration by repressing CD147 activity and subsequently downregulating the expression of MMP-2, MMP-9 were also revealed (16). Although this evidence reveals sinomenine as a potential agent in cancer treatment, whether sinomenine suppresses the growth of human osteosarcoma has not been previously investigated.

In this study, we revealed the in vitro and in vivo anti-proliferative and anti-metastatic effects of sinomenine on human osteosarcoma cells. We found that sinomenine effectively inhibited cell proliferation by inducing $S$ phase cell cycle arrest and colony formation in vitro. However, sinomenine showed little apoptotic inducement in $\mathrm{U}_{2} \mathrm{OS}$ and HOS cells at the dosages tested. Nevertheless, sinomenine suppressed neovascularization via regulating the related expression of VEGF and CD147. Additionally, sinomenine inhibited the invasion and migration by decreasing MMP-2 and MMP-9 secretion and activation through the CXCR4-STAT3 axis. Importantly, sinomenine prevented osteoclastogenesis by regulating the tumor-activated RANKL and reduced bone destruction in a mouse model. This study suggests sinomenine as a promising anti-metastatic drug in osteosarcoma adjuvant treatment.

\section{Materials and methods}

Cells culture. The human osteosarcoma (OS) cell lines, HOS and $\mathrm{U}_{2} \mathrm{OS}$ were purchased form Shanghai Institute of Cell Biology, Chinese Academy of Sciences (Shanghai, China). The human umbilical vein endothelial cells (HUVEC) were a gift from Dr Y.Q. Xie (Clinical Research Center, Second Affiliated Hospital of Zhejiang University, School of Medicine). The HOS and $\mathrm{U}_{2} \mathrm{OS}$ cells were cultivated with high-glucose Dulbecco's modified Eagle's medium (DMEM) and RPMI-1640 medium, respectively. Cells were incubated in $5 \% \mathrm{CO}_{2}$ humidified incubator supplemented with $10 \%$ fetal bovine serum (FBS) and $1 \%$ penicillin and streptomycin.

Reagents and antibodies. Sinomenine were purchased from Selleck Biochemistry (USA), and dissolved in PBS at a concentration of $500 \mathrm{mM}$ and stored at $-20^{\circ} \mathrm{C}$. The molecular formula of sinomenine is $\mathrm{C} 19 \mathrm{H} 23 \mathrm{NO} 4$ (Fig. 1A). Antibodies against CXCR4, phospho-STAT3, STAT3, MMP-9, MMP-2, GAPDH, TIMP-1, TIMP-2, CD147, RANKL, NK- $\mathrm{B}$, and phospho$\mathrm{NK}-\kappa \mathrm{B}$ were purchased form Cell Signaling Technology (USA) and Abcam (UK). VEGF antibody was purchased from Santa Cruz (USA). DMEM, RPMI-1640 medium, FBS, penicillin, streptomycin, PBS and $0.25 \%$ trypsin were purchased from Gibco/BRL (USA). CXCR4 inhibitor, Plerixafor (AMD3100), was purchased form Selleck (USA).

Cell viability assay. To assess the effects of sinomenine on proliferation of osteosarcoma cells, $\mathrm{HOS}$ and $\mathrm{U}_{2} \mathrm{OS}$ cells were seeded in 96-well plates at 5,000 cells/well and allowed to adhere for $12 \mathrm{~h}$. Varying concentrations of sinomenine were supplemented to $\mathrm{HOS}$ and $\mathrm{U}_{2} \mathrm{OS}$ cells, the cells then incubated with $5 \% \mathrm{CO}_{2}$ at $37^{\circ} \mathrm{C}$ for 24 and $48 \mathrm{~h}$, respectively. The media were removed and the cells added with $10 \%$ CCK- 8 (Dojindo, Japan) in $100 \mu 1$ DMEM or RPMI-1640 for $2 \mathrm{~h}$ at $37^{\circ} \mathrm{C}$. The absorbance was measured using a MR7000 microplate reader (Dynatech, NV, USA) at $450 \mathrm{~nm}$. Absorbance is directly proportional to the proliferation of cells.

Colony formation assay. The clonality of tumor cells is closely related to tumor recurrence. In order to assess the impact of sinomenine on the osteosarcoma cell monoclonal ability, clone formation assay was performed. Five hundred $\mathrm{HOS}$ or $\mathrm{U}_{2} \mathrm{OS}$ cells were seeded in 6-well plates and treated with different concentrations on the third day. The process was continued for 14 days or until cells had visible colonies. The cells were fixed in 4\% paraformaldehyde for $15 \mathrm{~min}$ and washed 2 times with PBS before staining with $0.1 \%$ crystal violet for $10 \mathrm{~min}$. The plates were photographed with ECL ChemiDoc imaging system (Bio-Rad, USA). The results were assessed by counting colonies using IPP software (Image Plus Pro).

Wound healing assay. The scratch migration assay is a classical method for assessing cell migration. $\mathrm{HOS}$ and $\mathrm{U}_{2} \mathrm{OS}$ cells were cultured in 6 -well plates to $80 \%$ density. Scratch was made using a $100-\mu 1$ pipette tip. Media was removed and the cells were treated with varying concentrations of sinomenine in DMEM or RPMI-1640 without FBS. The width of the denuded area was measured every $6 \mathrm{~h}$ under a microscope. Images were taken. The migration rate was calculated following the equation: migration rate $=$ (average original width - average final width) / average original width $\mathrm{x} 100 \%$.

Gelatin zymography assay. The gelatin zymography assay was used to evaluate the activities of gelatinase MMP-2 and 
A
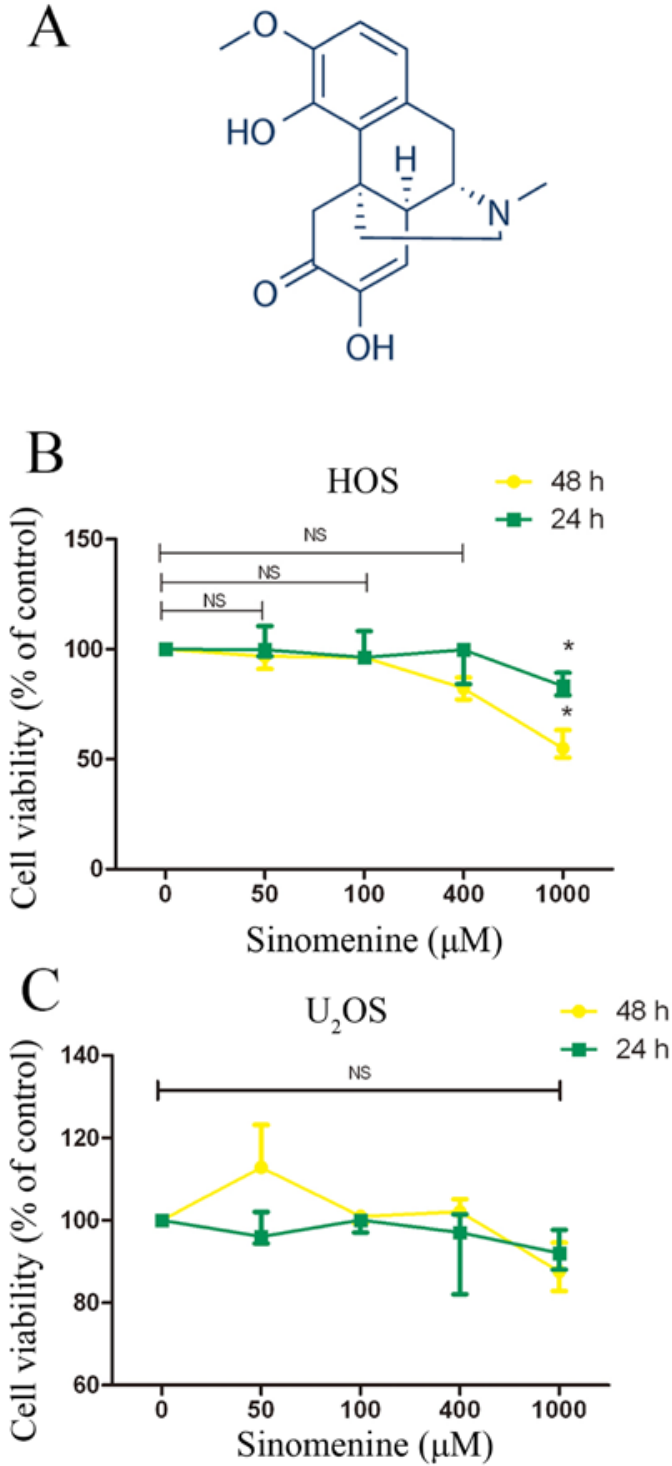

Figure 1. Cytotoxicity effect of sinomenine on HOS and $\mathrm{U}_{2} \mathrm{OS}$ cells. The growth inhibitory effects of sinomenine were examined by CCK-8 assay. (A) The chemical structure of sinomenine. HOS and $\mathrm{U}_{2} \mathrm{OS}$ cells were treated by different concentration of sinomenine. (B) Sinomenine shows little cytotoxicity to HOS cells at the concentration 50,100 and $400 \mu \mathrm{M}$ at both 24 and $48 \mathrm{~h}$, no statistically significant differences. Even when the concentration reached $1 \mathrm{mM}$, there was only $16.17 \%$ cell killing rate at $24 \mathrm{~h}$ and $33.76 \%$ at $48 \mathrm{~h}$. (C) Sinomenine shows little cytotoxicity to $\mathrm{U}_{2} \mathrm{OS}$ cells at the concentration 50,100 and $400 \mu \mathrm{M}$ and $1 \mathrm{mM}$ at both 24 and $48 \mathrm{~h}$. ${ }^{*} \mathrm{P}<0.05$, significantly different compared with control, NS, non-significant difference. All experiments were repeated three times.

MMP-9. HOS or $\mathrm{U}_{2} \mathrm{OS}$ cells were seeded in 6-well plates at $3 \times 10^{5}$ per well and cultivated for adherence. The cells were treated with different concentrations for $48 \mathrm{~h}$ and harvested by trypsinization. RIPA lysis buffer (Boster Biotechnology, Wuhan, China) was supplied for cell lysis for $30 \mathrm{~min}$ and then centrifuged for $15 \mathrm{~min}$ at $4^{\circ} \mathrm{C}$. Supernatant was collected to determine the total protein concentration using BCA Protein Assay kit (Beyotime Biotechnology, China). Equivalent amounts of protein samples were mixed with non-denatured loading buffer. Sodium dodecyl sulfate polyacrylamide gel electrophoresis (SDS-PAGE) (10\%) was performed with $0.1 \%$ gelatin at $80 \mathrm{~V}$, for $2-3 \mathrm{~h}$ at $4^{\circ} \mathrm{C}$. The gels were removed and incubated with activation buffer $(50 \mathrm{mM}$ Tris- $\mathrm{HCl}, 5 \mathrm{mM}$ $\mathrm{CaCl}_{2}, 1 \mu \mathrm{M} \mathrm{ZnCl}_{2}, 0.02 \% \mathrm{NaN}_{3}$ ) at $37^{\circ} \mathrm{C}$ for $48 \mathrm{~h}$. The gels were stained with $0.05 \%$ Coomassie blue (R-250) for $3 \mathrm{~h}$ and destaining in methyl alcohol, acetic acid destaining solution until clear bands were visible, then images were taken.

Transwell invasion assay. Transwell invasion assays were performed to assess osteosarcoma $\mathrm{HOS}$ and $\mathrm{U}_{2} \mathrm{OS}$ cell migration and invasion ability. The Martrigel (BD, USA) was applied to simulate the extracellular matrix (ECM), and 10,000 HOS or $\mathrm{U}_{2} \mathrm{OS}$ cells were seeded in the Transwell chamber in $200 \mu \mathrm{l}$ non-FBS medium with different concentrations of sinomenine and $500 \mu 120 \%$ corresponding FBS was placed in the lower 24-well plates. High serum concentration as a chemotactic factor stimulated OS cells to break through the Martrigel and to migrate from the chambers to the lower wells. The penetrated cells adhered on the lower chamber membranes, and their number were counted under three random high power fields. Images were taken under a microscope.

ELISA of MMP-2 and MMP-9 secretion. Cells were seeded at $3 \times 10^{5}$ per 6-well plate with suitable medium and treated with sinomenine the next day. The cells underwent treatment for $48 \mathrm{~h}$, then the supernatant was collected for enzyme-linked immunosorbent assay (ELISA). ELISA kit for secreted MMP-2 and MMP-9 were purchased from Boster Institution Biochemistry (Wuhan, China). The assay was performed following the manufacturer's instructions.

Tube formation assay. Matrigel was implanted in a 96-well plate at $100 \mu \mathrm{l}$ per well at $37^{\circ} \mathrm{C}$ overnight. HUVEC cells $\left(2 \times 10^{4}\right)$ or $\mathrm{U}_{2} \mathrm{OS}$ cells then were seeded in the wells with $100 \mu 11.5 \%$ FBS low-sugar DMEM or PRMI-1640 medium respectively (4 repeats). Different concentrations of sinomenine were given and the HUVEC cells were incubated. Images were first taken under a microscope at $3 \mathrm{~h}$ acquiring the tube-like structures formation, and then every one hour. The total tube length were measured by IPP software.

Western blot analysis. Cells were lysed in RIPA buffer (Beyotime, Shanghai, China). Total proteins were separated by $10 \%$ sodium dodecyl sulfate polyacrylamide gel electrophoresis (SDS-PAGE), and then transferred to a $0.22-\mu \mathrm{m}$ PVDF membrane (Millipore, Shanghai, China). After blocking with 5\% non-fat milk for $2 \mathrm{~h}$, the membranes were incubated overnight at $4^{\circ} \mathrm{C}$ with antibodies. Horseradish peroxidase (HRP)-conjugated goat anti-mouse (1:1,500, Thermo Pierce) or goat anti-rabbit IgG $(1: 1,500$, Thermo Pierce) was applied as secondary antibody for $1 \mathrm{~h}$ at room temperature. The immunoreactive bands were detected using an enhanced chemiluminescent detection reagent (Pierce) and exposured by ChemiDoc imaging system (Bio-Rad).

Human osteosarcoma orthotopic experiment. Four-week-old, female BALB/c-nude mice were purchased from Shanghai Laboratory Animal Center of Chinese Academy of Sciences. The HOS cells were transfected luciferase (HOS-Luc) for imaging in vivo. The tumors were established by injecting $50 \mu 1$ PBS containing 10x10 ${ }^{6}$ HOS-Luc resuspension cells into the left tibia marrow cavity using $1 \mathrm{ml}$ injection through 
upper tibia tubercle from the knee. Six mice were not injected as non-tumor negative control. At the 10th day after HOS-Luc injection, luciferase-imaging was performed to make sure the tumor tissue located in orthotopic tibia and the total tumor number reached $10 \times 10^{7}$. The mice with very low luciferase signal, or tumor tissues not located in the tibia were sacrificed. Then the sinomenine treatment was carried out. The mice were divided into two group randomly (6 mice each group), to receive intraperitoneal rejection of $200 \mu 1 \mathrm{PBS}$ or $150 \mathrm{mg} / \mathrm{kg}$ sinomenine. The treatment lasted for 14 days, the body weight was determined every 2 days. As the tumor located in the tibia cavity with an irregular shape, it is difficult to measure the tumor volume. Luciferase fluorescent signal was detected every week to estimate the tumor growth. All the mice were sacrificed at day 14 after treatment. The venous blood was collected from the mouse orbita for blood biochemical tests. The tumor tissues were dissected and fixed in formalin.

All the procedures involving clinical specimens were approved by the Research Ethics Committee of the Second Affiliated Hospital of Zhejiang University School of Medicine, China.

Immunofluorescent staining for histology of Ki-67. The $\mathrm{Ki}-67$ potein, as a marker of cell proliferation, is used in evaluating the tumor differentiation, invasion, metastasis and prognosis. The Ki-67 antibody was purchased from Cell Signaling Technology (CST, USA). The dewaxed slices received antigen retrieval and were blocked by $2 \%$ goat fetal serum for $1 \mathrm{~h}$, and then incubated with $\mathrm{Ki}-67$ antibody for $2 \mathrm{~h}$ at room temperature. The fluorescent secondary antibody (Alexa Fluor ${ }^{\circledR}$ 488, ZSGB-BIO, Beijing, China) was added and incubated with the slices for $1 \mathrm{~h}$ and the DAPI staining for nucleus location for $5 \mathrm{~min}$. After two PBS washes and resin mounting, the results were observed under a fluorescence microscope and images were taken. The images were merged using IPP software.

TRAP staining. In order to evaluate the tumor-associated osteolysis in tibia, tartaric acid alkaline phosphatase (TRAP) stain was performed. In brief, the dewaxed slices were washed twice with PBS, and then the manufacturer's instructions (Keygen Biotech, Nanjing, China) were followed. The results were observed under a microscope after gradient alcohol dehydration and resin mounting. The images were taken and merged by IPP software.

$X$-ray for orthotopic human osteosarcoma in nude mouse tibia. X-ray treatment was implemented to estimate the tumorassociated osteolysis in tibia. The legs with the orthotopic human osteosarcoma in tibia cavity were resected from middle of femur and fixed in formalin. All the samples underwent X-rays.

Tumor histology. Paraffin sections were dewaxed and hematoxylin and eosin stained. In order to better demonstrate bone destruction by tumor-associated osteolysis in tibia, fast green staining was applied.

Statistical analysis. Statistical analysis was performed with SPSS 17.0 software. Statistical significance was determined using two-tailed Student's t-test when comparing two groups. All experiments were performed at least in triplicate and the data are presented as mean $\pm \mathrm{SD}$ with a P-value of $\leq 0.05$ considered as statistically significant.

\section{Results}

Sinomenine shows little cytotoxic effect on $\mathrm{HOS}$ and $\mathrm{U}_{2} \mathrm{OS}$ cells. In order to assess whether sinomenine had immediate toxic effect on osteosarcoma cells, the osteosarcoma cell lines $\mathrm{HOS}$ and $\mathrm{U}_{2} \mathrm{OS}$ were exposed to different concentrations of sinomenine with 24 and $48 \mathrm{~h}$. The cell viability was evaluated by CCK- 8 assay. Sinomenine showed slight cytotoxicity on both $\mathrm{HOS}$ and $\mathrm{U}_{2} \mathrm{OS}$ cells (Fig. $1 \mathrm{~B}$ and $\mathrm{C}$ ) at the concentration of 50, 100 and $400 \mu \mathrm{M}$, and also $1 \mathrm{mM}$ in HOS (Fig. 1B). We considered it might be difficult to achieve blood drug concentration in the subsequent experiment in vivo. The inhibitory effect of sinomenine on invasion and migration in malignancy has been reported (17). So our research focused on the inhibition of sinomenine in invasion and migration in osteosarcoma.

Sinomenine induces $S$ phase arrest by regulating cell cycle regulators. To determine whether sinomenine inhibits cell proliferation by inducing cell cycle arrest, we detected the cell cycle distribution in cells treated with sinomenine. The results showed that sinomenine led to accumulation in $\mathrm{S}$ phase in both HOS and $\mathrm{U}_{2} \mathrm{OS}$ cells (Fig. 2A and B). The quantitative analysis indicated significant differences in $\mathrm{S}$ phase (Fig. 2C). To elucidate the mechanisms, western blot analysis was performed to measure the expression of cell cycle regulated proteins. Treatment increased the phosphoChk2 and it might be caused by sinomenine-induced DNA damage. The phospho-Chk2 activated the $\mathrm{p} 21$, which could be stimulated by phospho-p53. The activity of Cyclin A-CDK2 complex was inhibited by upregulated p21 which contributed to promote cell cycle from $S$ phase into G2/M phase (Fig. 2D and $\mathrm{E}$ ). The data suggest that sinomenine induces $\mathrm{S}$ phase arrest by altering cell cycle regulation induced by DNA damage.

Sinomenine inhibits clone formation in osteosarcoma cells. The residual tumor cells from chemotherapy or operation might lead to tumor recurrence depending on the cell monoclonal ability. The results showed that $400 \mu \mathrm{M}$ sinomenine inhibited the colony formation markedly in both HOS and $\mathrm{U}_{2} \mathrm{OS}$ cells. There was an obvious decline in clone number and size (Fig. 3). It suggests that sinomenine inhibits the monoclonal ability in osteosarcoma cells.

Sinomenine inhibits invasion and migration in HOS and $\mathrm{U}_{2} \mathrm{OS}$. We investigated the effect of sinomenine on invasion and migration in $\mathrm{HOS}$ and $\mathrm{U}_{2} \mathrm{OS}$ cells by wound healing and Transwell Matrigel assays. Treated HOS and $\mathrm{U}_{2} \mathrm{OS}$ cells show less migration into the scratched zone (Fig. 4A and B). The migration rate deceased from 81.13 to $62.62 \%$ in HOS and 70.72 to $49.61 \%$ in $\mathrm{U}_{2} \mathrm{OS}$ cells (Fig. $4 \mathrm{C}$ and D). The Matrigel was used to simulate the ECM in Transwell invasion assay. Less $\mathrm{HOS}$ and $\mathrm{U}_{2} \mathrm{OS}$ cells digested the Matrigel to go through the Boyden chamber membrane after $400 \mu \mathrm{M}$ sino- 
A

Sinomenine Control $50(\mu \mathrm{M})$ $100(\mu \mathrm{M})$ $400(\mu \mathrm{M})$
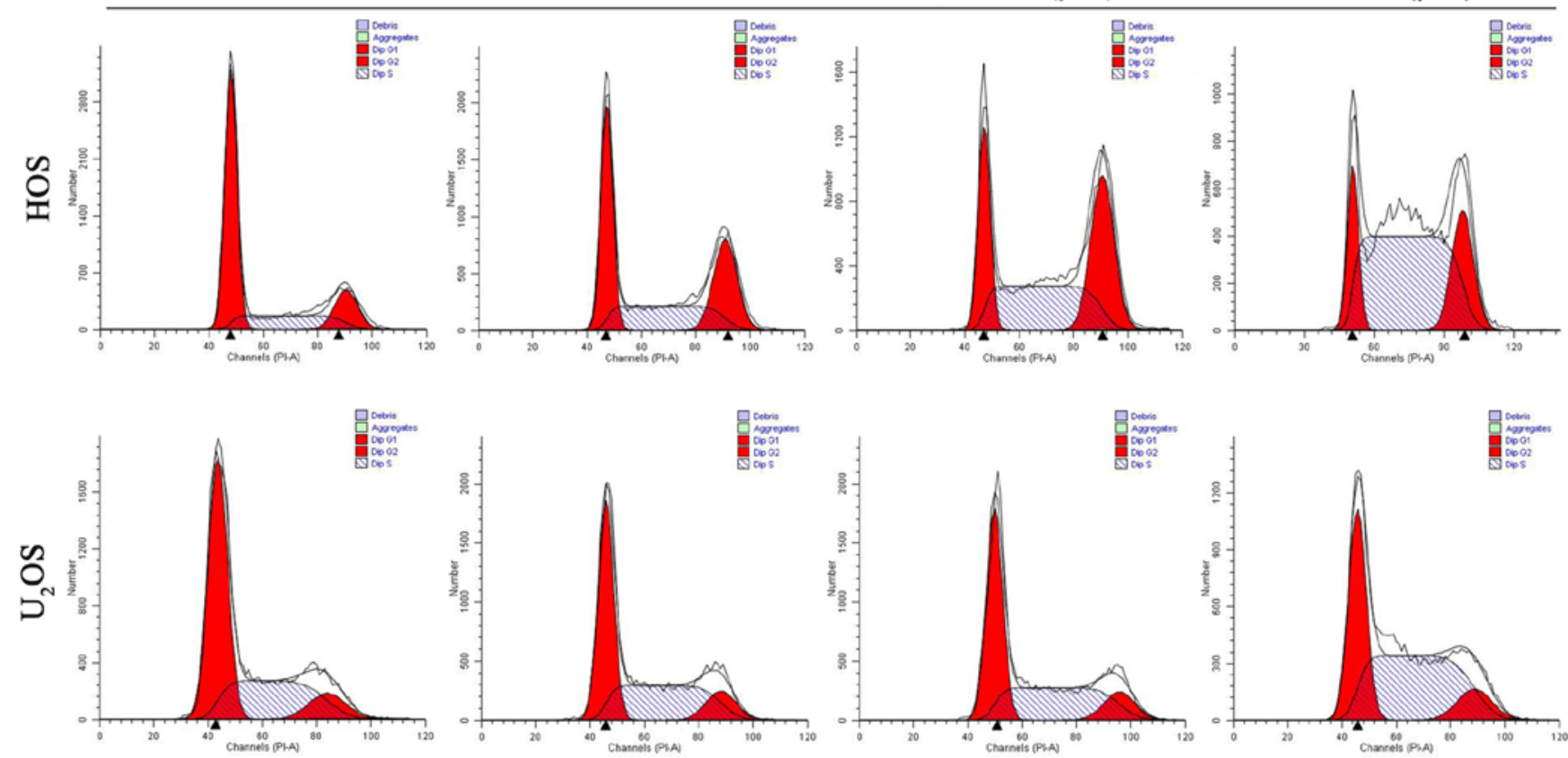

B
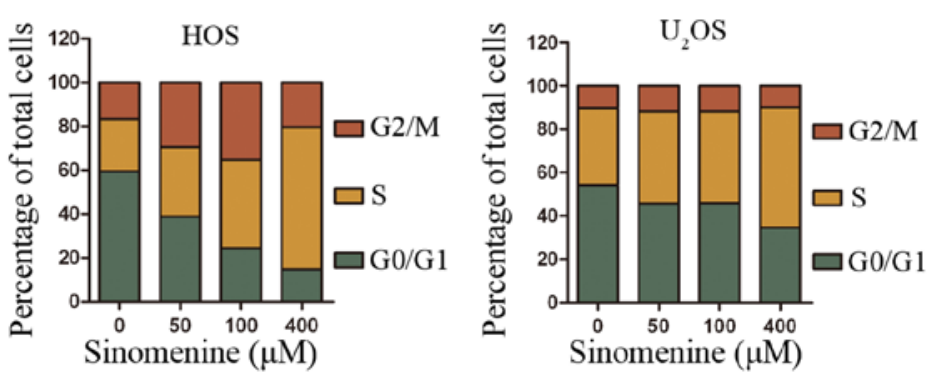

S phase arrest
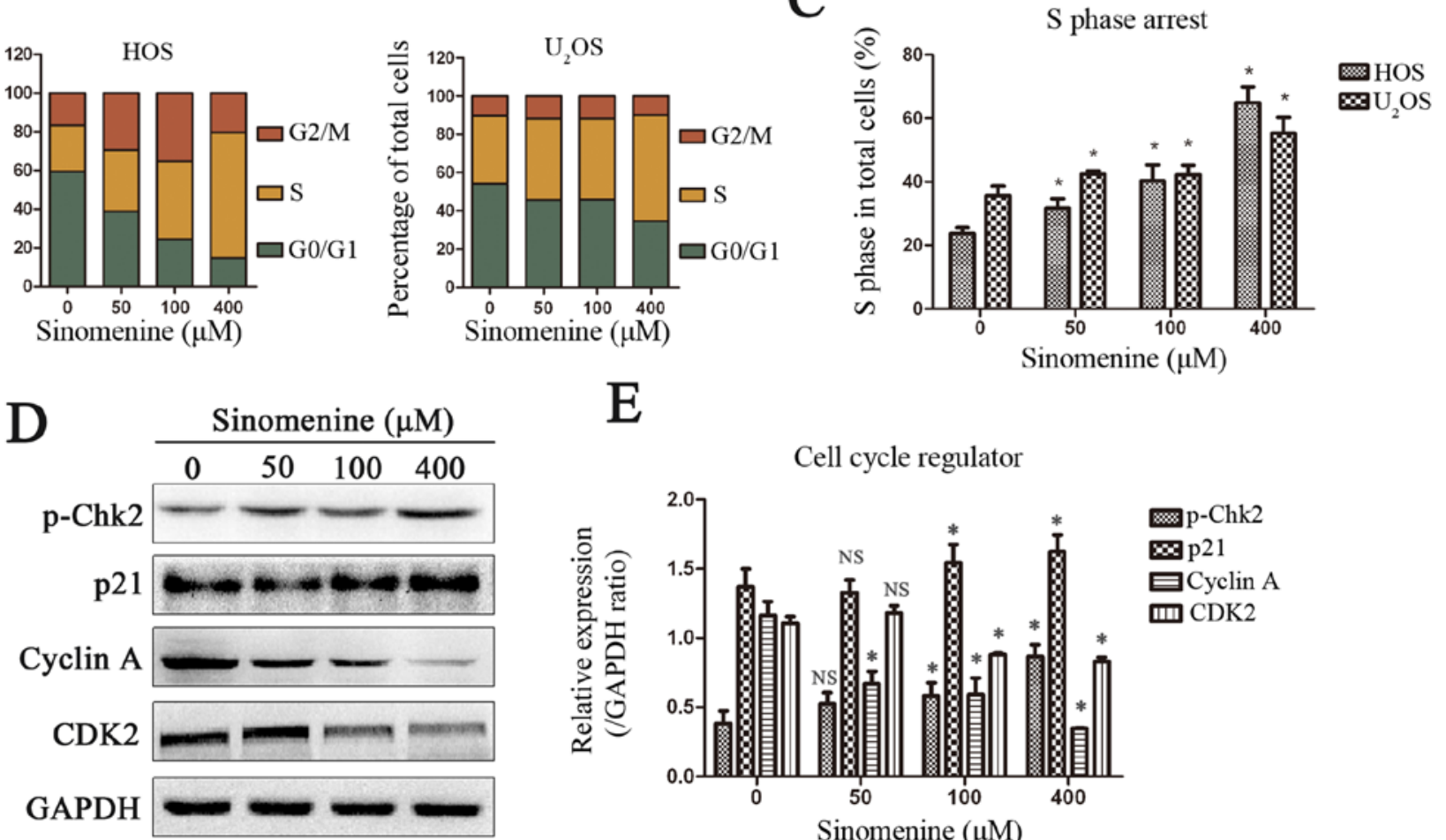

$\mathrm{E}$

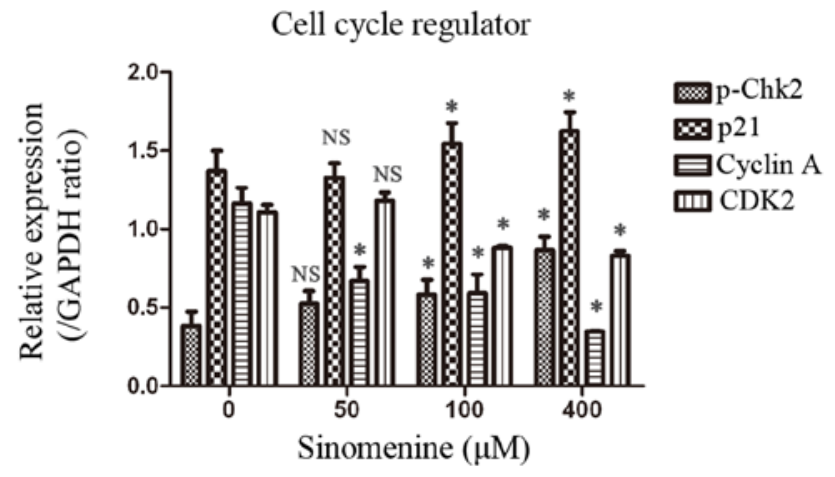

Figure 2. Sinomenine induces S phase arrest and modulates cell cycle regulatory proteins in osteosarcoma. (A) Sinomenine induced S phase arrest in HOS and $\mathrm{U}_{2} \mathrm{OS}$ cells. Cells were incubated with sinomenine for $24 \mathrm{~h}$ and then fixed with $75 \%$ ethyl alcohol. The fixed cells were stained with PI and analyzed by flow cytometry. (B) The percentage of cell cycle distribution is presented as the mean \pm SD from three independent experiments. (C) Quantitative analysis of S phase percentages of HOS and $\mathrm{U}_{2} \mathrm{OS}$. (D and E) Cells were treated with sinomenine for $24 \mathrm{~h}$. The expressions of S phase cell cycle-regulating proteins were measured by western blot analysis. The bands were quantitatively analyzed by ImageJ software and the relative expression is presented. Data represent triplicate values and are expressed as the means $\pm \mathrm{SD}$ of three independent experiments. ${ }^{*} \mathrm{P}<0.05$, significant different compared with control.

menine treatment at $24 \mathrm{~h}$ (Fig. 4E). The average number of invading cells reduced from 173 to 38 in HOS and 66 to 16 in $\mathrm{U}_{2} \mathrm{OS}$ cells per field at $400 \mu \mathrm{M}$ (Fig. 4F). Overall, these results clearly indicate that sinomenine inhibits not only migration, but also invasion significantly in osteosarcoma.
Anti-vasculogenic activity in osteosarcoma of sinomenine. Angiogenesis is considered playing a central role in tumor unrestrained growth and development of metastases (18). We tested the effet of sinomenine on anti-vasculogenic activity. The sinomenine treated HUVECs (human umbilical vein 


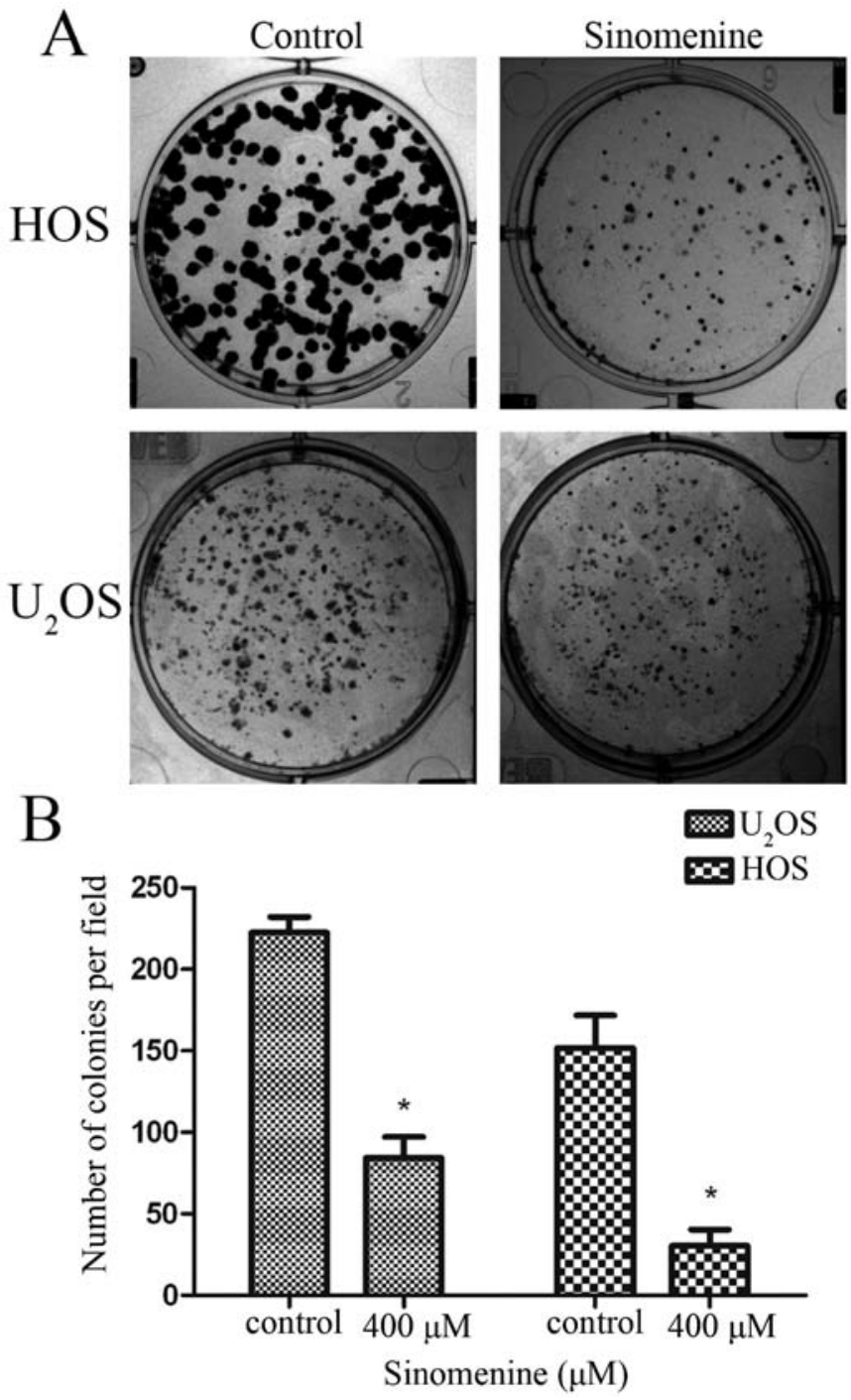

Figure 3. Sinomenine inhibits the clone formation in $\mathrm{HOS}$ and $\mathrm{U}_{2} \mathrm{OS}$ cells. (A) $\mathrm{HOS}$ and $\mathrm{U}_{2} \mathrm{OS}$ cells were incubated with sinomenine at concentration of $400 \mu \mathrm{M}$. The treatment lasted $\sim 2$ weeks until colonies were visible. (B) Colony number of $\mathrm{HOS}$ and $\mathrm{U}_{2} \mathrm{OS}$ cells. Data represent the values of triplicates and are expressed as the means \pm SD of three independent experiments. " $\mathrm{P}<0.05$, significantly different compared with control group.

endothelial cells) showed lower tube formation ability than control group dose-dependently (Fig. 5A). The relative tube length was estimated by IPP software. Fig. 5B shows relative tube length of treated-group reduced by $60.51 \%$ compared to control group at the concentration of $400 \mu \mathrm{M}$.

Previous studies have reported that $\mathrm{U}_{2} \mathrm{OS}$ cells have the ability to form tumor tube-like structures under hypoxicischemic conditions. We investigated the inhibiting effect of sinomenine on tumor tube-like formation in $\mathrm{U}_{2} \mathrm{OS}$ cells. The results demonstrated that $\mathrm{U}_{2} \mathrm{OS}$ cells had the capacity to form tube-like structures in vitro in Matrigel and under low FBS conditions, and this can be inhibited by sinomenine (Fig. 5C and $\mathrm{D}$ ). The vascular endothelial growth factor (VEGF) is considered indispensable in tumor associated neovascularization (19). CD147, also named basigin or emmprin, is demonstrated to induce angiogenesis via stimulation of VEGF production. Furthermore, in tumors, CD147 most likely stimulates matrix metalloproteinase production (20).
In order to investigate the mechanism of anti-neovascularization of sinomenine, western blot analysis was performed to measure the expression of VEGF and CD147. A significant decrease was observed after treatment (Fig. 5E-G).

Sinomenine inhibits the expression, secretion and activity of MMP-2 and MMP-9. Matrix metalloproteinase (MMP) plays a crucial role in ECM degradation in tumorigenic processes, especially the gelatinase, MMP-2 and MMP-9. Gelatin zymography was performed to estimate the enzymatic activity of MMP-2 and MMP-9. Supernates collected from treated $\mathrm{HOS}$ and $\mathrm{U}_{2} \mathrm{OS}$ cells showed a narrower band and indicated less gelatinase activities in a dose-dependent manner (Fig. 6A). The results of zymography quantitative analysis showed no significant difference in HOS except at $400 \mu \mathrm{M}$ concentration of MMP-2. Whereas, marked decline was observed in $\mathrm{U}_{2} \mathrm{OS}$ cells (Fig. 6B and C). ELISA of supernates for MMP-2/-9 provided similar results, with a better inhibition in $\mathrm{U}_{2} \mathrm{OS}$ than HOS cells (Fig. 6D). ELISA was performed to detect the external secretion of MMP-2 and MMP-9 by osteosarcoma cells. The secretion of MMP-2 in $\mathrm{HOS}$ and $\mathrm{U}_{2} \mathrm{OS}$ was declined from 242.62 to $148.28 \mathrm{ng} /$ $\mathrm{ml}$ and 190.26 to $86.76 \mathrm{ng} / \mathrm{ml}$ respectively. On the contrary, the secretion of MMP-9 in HOS and $\mathrm{U}_{2} \mathrm{OS}$ decreased from 220.25 to $123.43 \mathrm{ng} / \mathrm{ml}$ and 162.62 to $24.61 \mathrm{ng} / \mathrm{ml}$, respectively (Fig. 6D). Western blot analysis was performed to measure the protein experession of MMP-2 and MMP-9, and, its tissue inhibitor TIMP-1 and TIMP-2 semi-quantitative gray values were calculate by IPP software. The results showed that the expression of MMP-2 and MMP-9 had decreased, and TIMP-1 and TIMP-2 increased correspondingly after sinomenine treatment in both HOS and $\mathrm{U}_{2} \mathrm{OS}$ cells (Fig. 6E and F). Overall, these results clearly demonstrate that sinomenine inhibits not merely the enzymatic activity of MMP-2 and MMP-9, but also the expression resulting in reduction of the secretions.

Inhibition of CXCR4 downregulates MMP-2 and MMP-9 expression and suppresses invasion in $\mathrm{U}_{2} \mathrm{OS}$. It has been reported that CXCR4 signaling activates the STAT3 pathway and contributes to invasion, metastasis and tumorigenesis in many types of cancers. We obtained primary cells derived from three patients suffering from osteosarcoma and the expression of CXCR4 was assessed by western blot analysis. The expression of CXCR4 was increased in osteosarcoma primary cells (OS1, OS2 and OS3, Fig. 7A) compared with hFOB cells (human fetal osteoblast). The expression of MMP-2 and -9 was downregulated through inhibiting CXCR4 by plerixafor, and the inhibition could be reversed by CXCR4 activator SDF-1 (Fig. 7B). The invasion potential also decreased when we blocked the CXCR4 pathway by its specific inhibitor plerixafor, and the inhibition could be reversed by CXCR4 activator SDF-1 (Fig. 7C). Similar results were observed in sinomenine treatment groups (Fig. 7B-D). The evidence demonstrated that CXCR4 plays an important role in contributing to invasion in osteosarcoma by regulating the expression of MMP-2 and MMP-9. Based on the outcomes between plerixafor and sinomenine treatment, we speculate that CXCR4 is the core site for sinomenine therapy. 

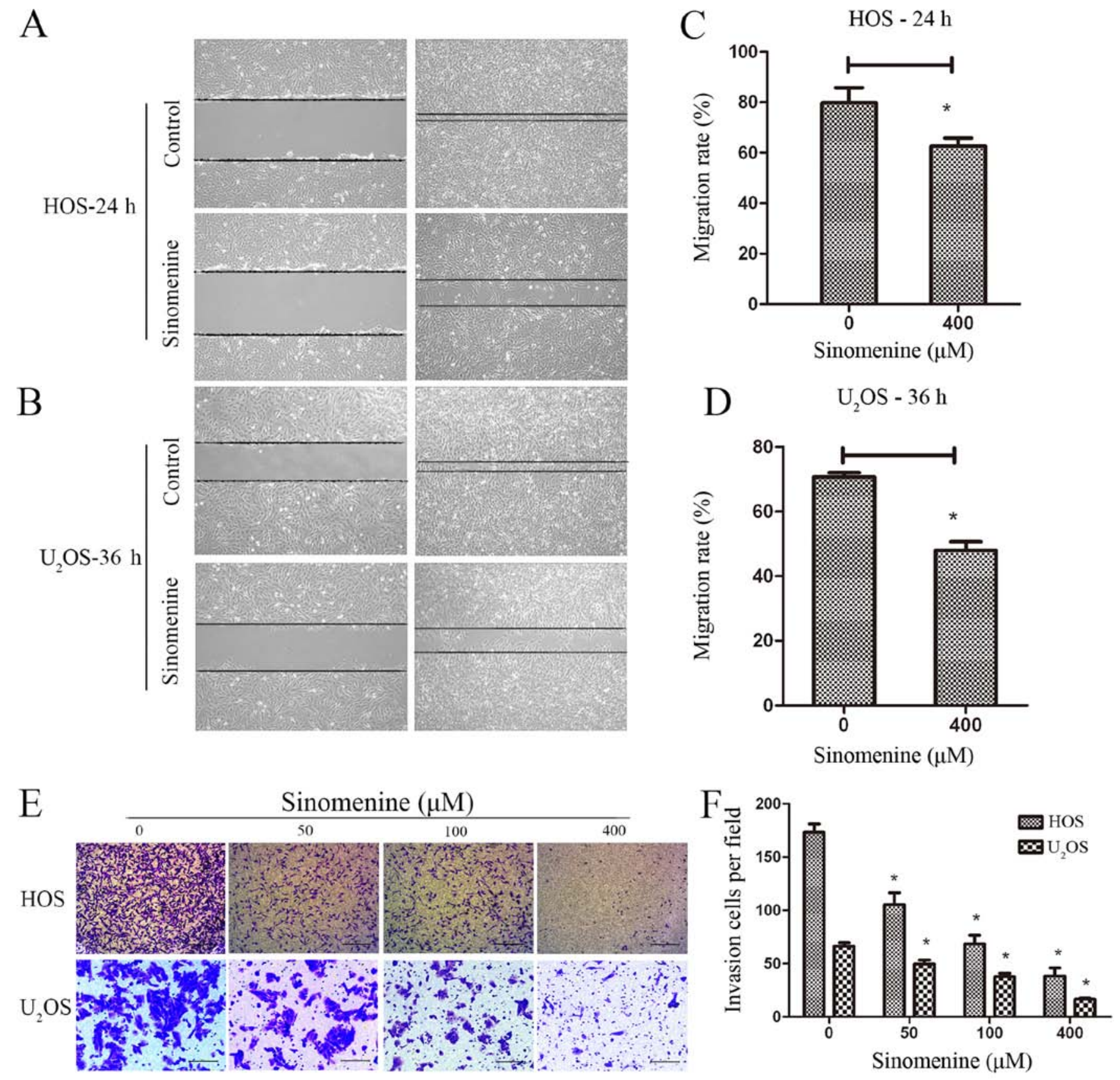

Figure 4. Sinomenine inhibits invasion and migration in HOS and $\mathrm{U}_{2} \mathrm{OS}$ cells. (A and B) HOS and $\mathrm{U}_{2} \mathrm{OS}$ cells were incubated with various concentrations of sinomenine for 24 and $36 \mathrm{~h}$, respectively. Migration to the wounded area was captured (x100 magnification) and statistics analyzed. (C and D) The wound area after treatment with sinomenine was quantified in three fields for each treatment. (E) Transwell assay was performed to assess the invasion abilities. HOS and $\mathrm{U}_{2} \mathrm{OS}$ cells were treated with different concentrations of sinomenine for $24 \mathrm{~h}$. Invasive cells were captured (x200 magnification). (F) Cells were counted in four random fields and analyzed. Data are expressed as the means $\pm \mathrm{SD}$ of triplicates. ${ }^{*} \mathrm{P}<0.05$, compared with the control group.

Sinomenine inhibits invasion through CXCR4-STAT3 pathway. Sinomenine treatment inhibited expression of CXCR4 and the STAT3 phosphorylation according to western blot and immunofluorescence analysis (Fig. 8A-C, $\mathrm{H}$ and I) as well as the expression of RANKL and NF- $\mathrm{kB}$ (p65) phosphorylation (Fig. 8A, D and E). The downregulated expression of CXCR4 by sinomenine was activated via SDF-1 and subsequently upregulated the expression of RANKL, VEGF, MMP-2 and MMP-9 (Fig. 8F and G) which indicated CXCR4 playing a key role in sinomenine treatment to regulate STAT3 phosphorylation and RANKL, VEGF, MMP-2/-9 expression downstream.
All these studies prove that sinomenine inhibits invasion and metastasis through suppressing CXCR4 and STAT3 phosphorylation and then downregulating expression of MMP-2 and -9 , VEGF and RANKL.

Sinomenine inhibits proliferation and osteolysis destruction of osteosarcoma in vivo. In vivo effect on osteosarcoma was detected via intraperitoneal administration of sinomenine in tumor orthotopic mouse model at $150 \mathrm{mg} / \mathrm{kg}$. The HOS-Luc cells were injected in left tibia cavity. The tumor samples were harvested by abscission from middle femoral. H\&E 
A $\quad$ Sinomenine $(\mu \mathrm{M})$ treated HUVEC
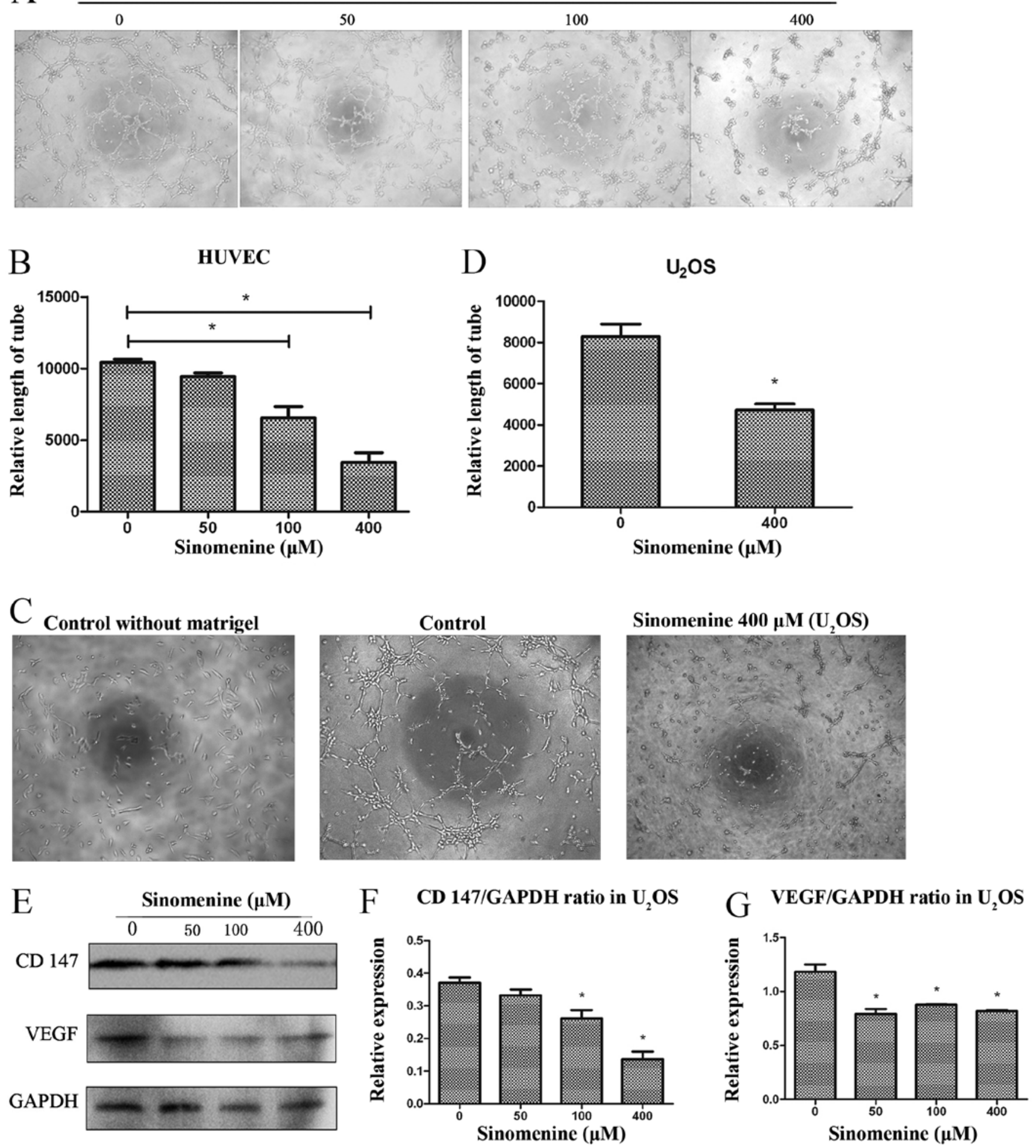

Fiugre 5. Sinomenine attenuates tube formation in HUVEC and $\mathrm{U}_{2} \mathrm{OS}$ cells and suppresses the angiogenesis related expression of CD147 and VEGF in $\mathrm{U}_{2} \mathrm{OS}$. (A) Tube formation assay in HUVEC (x100 magnification). (B) Sinomenine inhibits the tube formation in HUVEC at concentration of 100 and $400 \mu$ M markedly. The relative tube length is presented as the mean \pm SD of three independent experiments. (C and $D)$ Tube formation assay in $\mathrm{U}_{2} \mathrm{OS}$ cells (x100 magnification). $\mathrm{U}_{2} \mathrm{OS}$ cells form tube-like structures in conditions with low-FBS and Matrigel. Sinomenine treatment suppresses $\mathrm{U}_{2} \mathrm{OS}$ tube-like formation. (E-G) Sinomenine treatment downregulates the angiogenesis related protein expression of CD147 and VEGF. Results are expressed as as the means \pm SD of three independent experiments. $\mathrm{P}<0.05$, significantly different compared with the control.

staining and fast green staining was carried out to observe osteolysis destruction of the mouse tibia. The typical spindle osteosarcoma cells and visible myxoid degeneration were observed in H\&E sections. Osteosarcoma cells infiltrated into bone cortex and marrow cavity. Double-nuclear or multinuclear osteosarcoma cells infiltrated in bone cortex inducing 

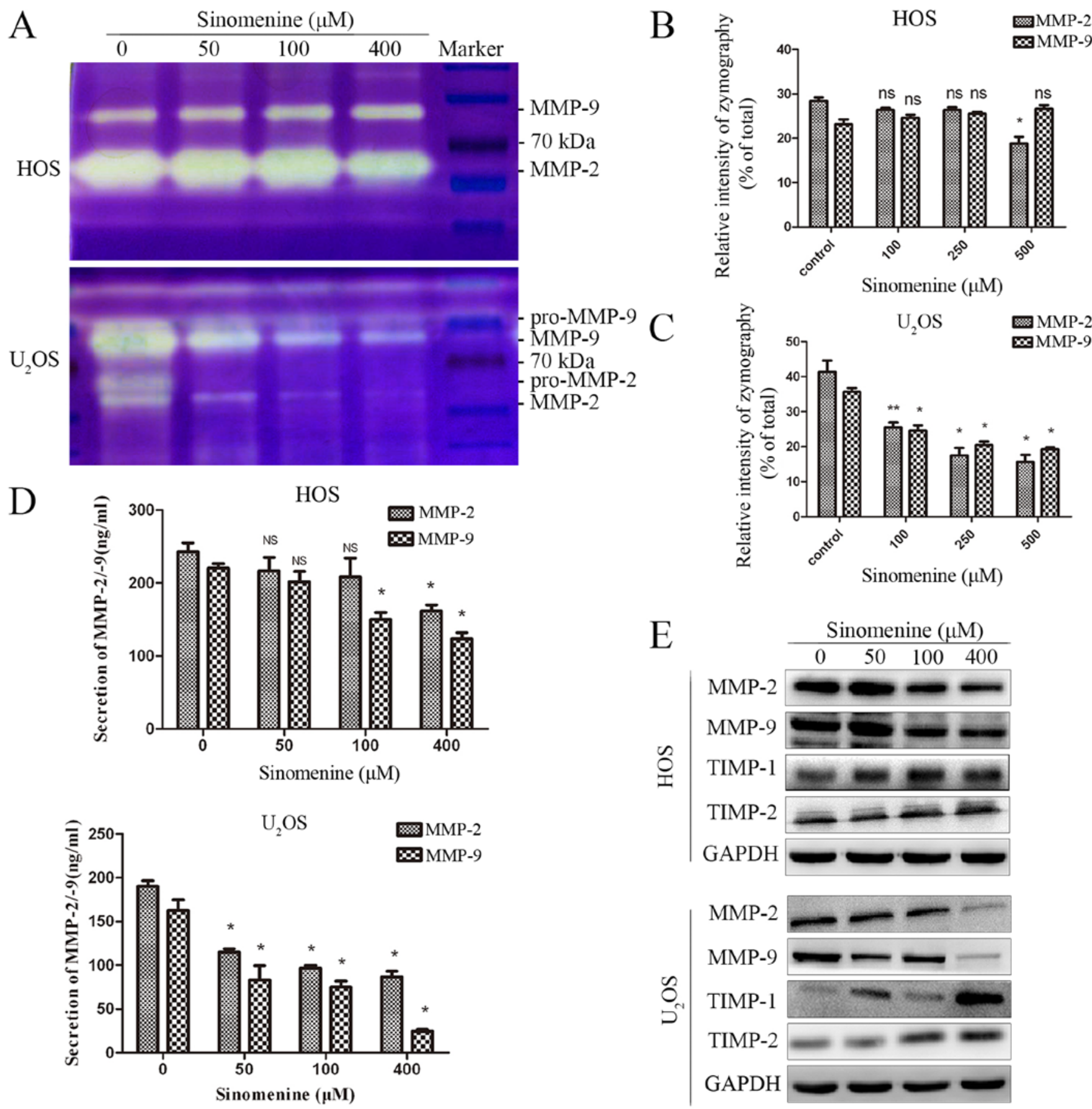

E
온
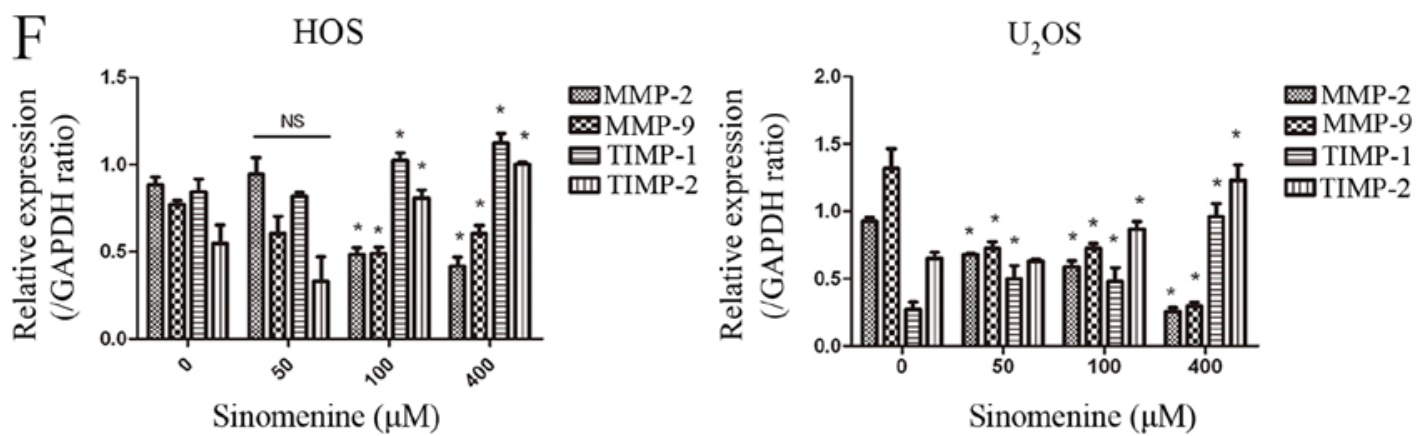

Figure 6. Sinomenine inhibits the activities, protein expression and secretion of MMP-2 and MMP-9 and regulates the expression of TIMP-1 and TIMP-2 in osteosarcoma. The HOS and $\mathrm{U}_{2} \mathrm{OS}$ cells were incubated with different concentration of sinomenine for $48 \mathrm{~h}$. The cells were collected and lysed for western blot analysis. The supernates were collected for gelatin zymography and ELISA. (A) The gelatin zymography of HOS and $\mathrm{U}_{2} \mathrm{OS}$. (B and C) Statistics of gelatin zymography. (D) ELISA of secretion MMP-2 and MMP-9. (E and F) The western blot analysis of MMP-2, MMP-9, TIMP-1, and TIMP-2. Results are expressed as means $\pm \mathrm{SD}$ of three independent experiments. ${ }^{*} \mathrm{P}<0.05$, significantly different versus the control. NS, no significance. 


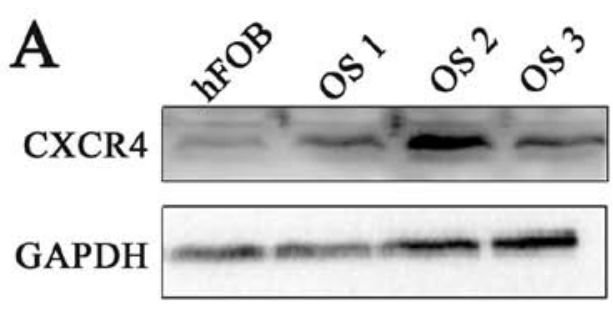

$\mathrm{C}$
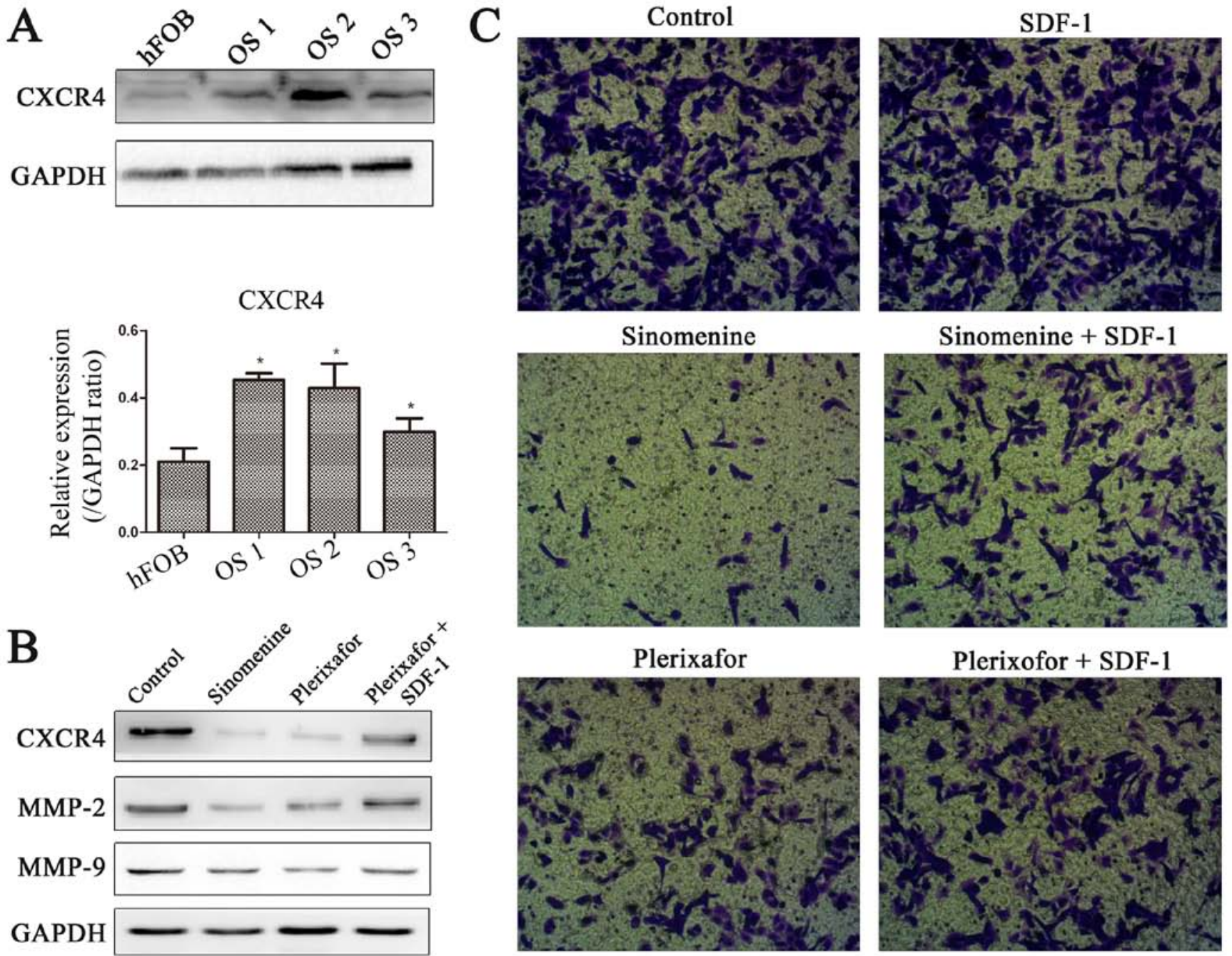

\section{Transwell invasion assay}
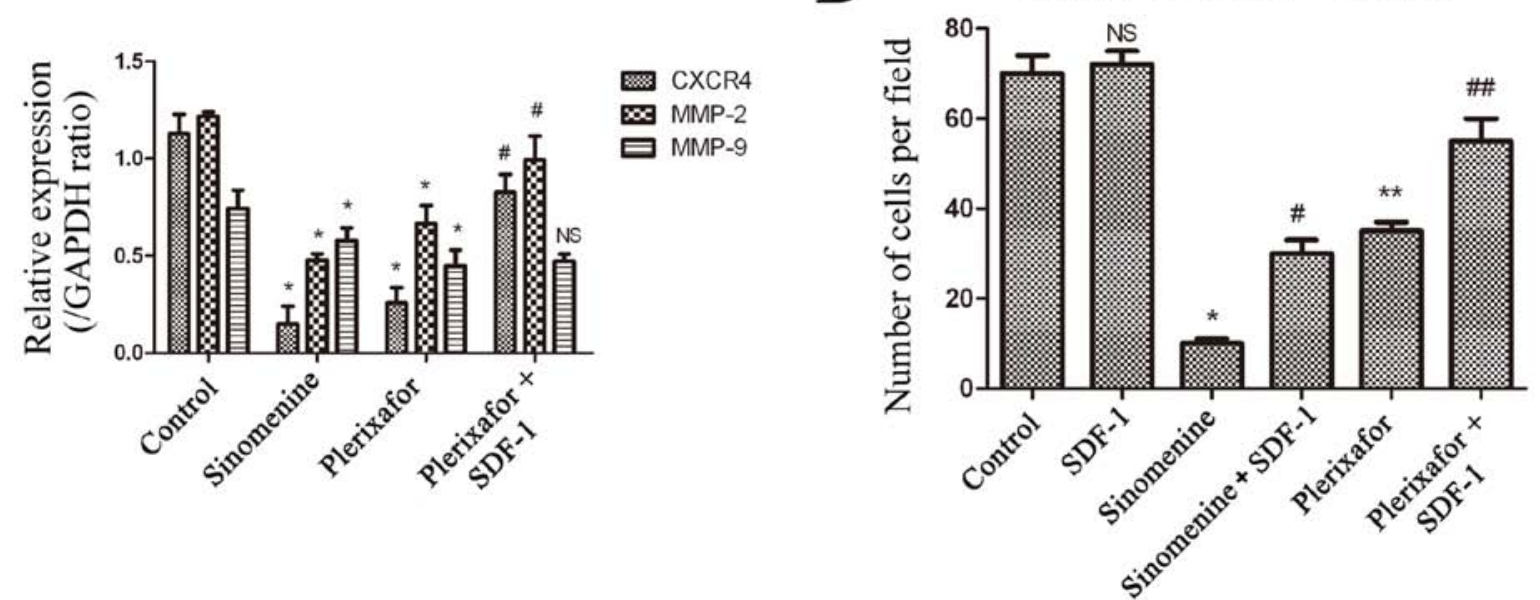

Figure 7. CXCR4 is overexpressed in primary osteosarcoma cells and promotes invasion in $\mathrm{U}_{2} \mathrm{OS}$ cells. (A) We obtained primary cells derived from three patients suffering from osteosarcoma. The splitting of tumor tissues were performed by western blot analysis. The expression of CXCR4 in primary osteosarcoma cells were detected. OS1, OS2, OS3, three primary osteosarcoma cells. (B) Suppression of CXCR4 by plerixafor (CXCR4 inhibitor, $500 \mathrm{ng} / \mathrm{ml}, 48 \mathrm{~h}$ ) downregulates the expression of MMP-2 and MMP-9. The downregulation can be reversed by SDF-1 (100 ng/ml, pre-incubate for $2 \mathrm{~h}$ ). Sinomenine treatment had similar effect to plerixafor. The bands were quantitative analyzed by ImageJ software. ${ }^{~} \mathrm{P}<0.05$, versus control. NS, no significance. ${ }^{~} \mathrm{P}<0.05$ compare with plerixafor treatment. (C) Cells were treated with plerixafor and sinomenine, with or without SDF-1 simultaneously for $24 \mathrm{~h}$. Then cells were harvested for Transwell assay. Representative images are presented. (x200 magnification). (D) Quantitative analysis of Transwell assay is shown in the histograms. *** $\mathrm{P}<0.05$, versus control; ${ }^{\#} \mathrm{P}<0.05$ versus sinomenine treatment; ${ }^{\# \#} \mathrm{P}<0.05$ versus plerixafor treatment. NS, no significance. Experiments were repeated three times.

osteolysis were viewed under high power field (Fig. 9C, H\&E staining, control group). The tumor cells invaded perios- teum inducing classical Codman triangle in osteosarcoma (Fig. 9C, H\&E staining, sinomenine-treatment group, high 

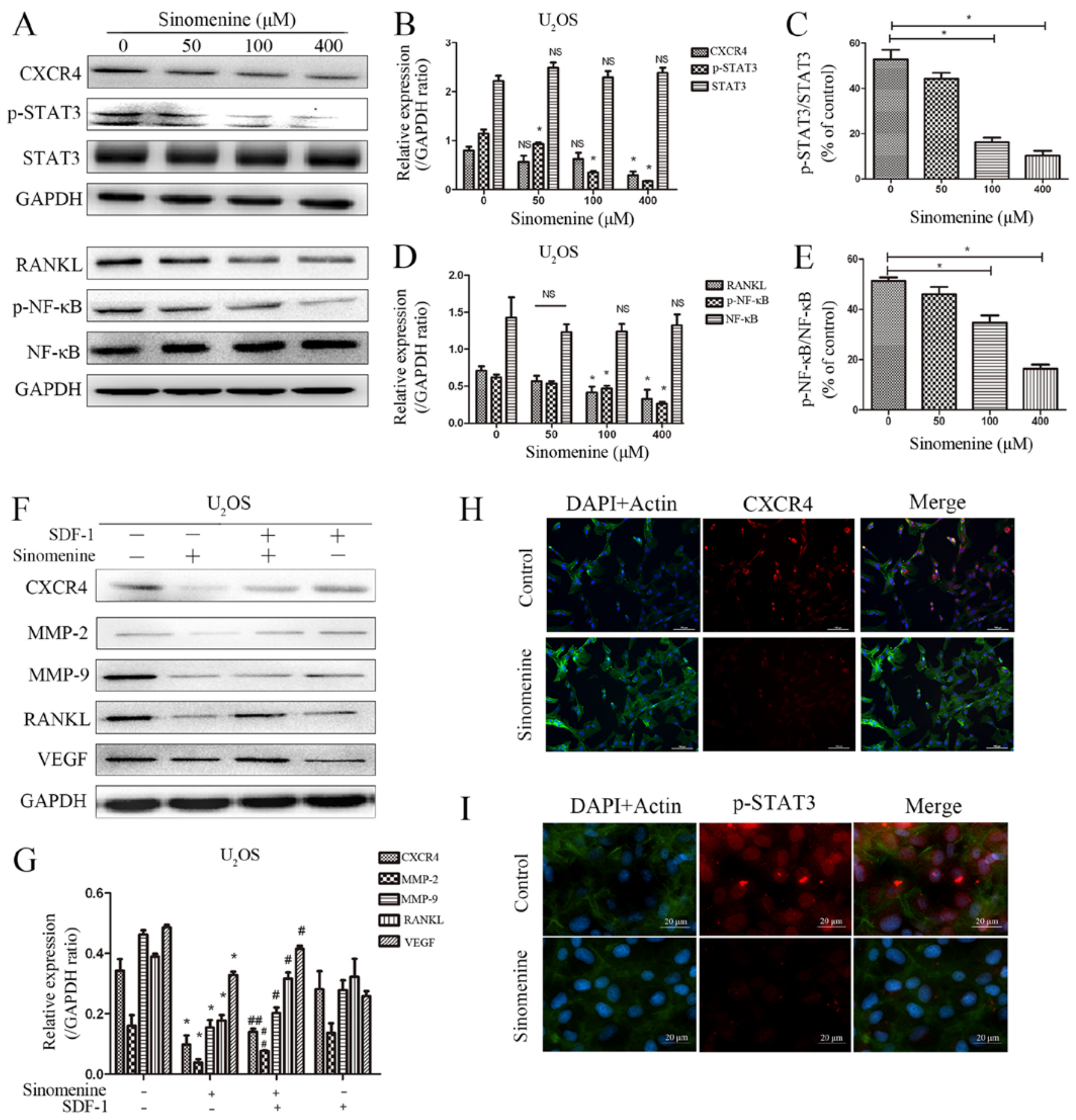

Figure 8. Sinomenine inhibits invasion via suppressing CXCR4 and phospho-STAT3 pathway, and regulates the expression of RANKL, phospho-NK-kB The inhibition can be reversed by SDF-1 in $\mathrm{U}_{2} \mathrm{OS}$. (A-E) Sinomenine downregulates expression of CXCR4, phospho-STAT3, RANKL and phospho-NK- $\mathrm{BB}$, the expression of STAT3 and NK-kB were upregulated slightly in $\mathrm{U}_{2} \mathrm{OS}$ cells. ${ }^{*} \mathrm{P}<0.05$, compared with control, NS, no significance. (F and $\mathrm{G}$ ) The $\mathrm{U}_{2} \mathrm{OS}$ cells were incubated with sinomenine and with or without SDF-1 (100 ng/ml, pre-incubate for $2 \mathrm{~h}$ before sinomenine) for $48 \mathrm{~h}$, the cells were harvested for western blot analysis. ${ }^{*} \mathrm{P}<0.05$, compared with control; ${ }^{\#} \mathrm{P}<0.05$, compared with sinomenine treatment; ${ }^{\# \#} \mathrm{P}<0.01$, compared with sinomenine treatment. (H and I) Immunofluorescent staining for $\mathrm{U}_{2} \mathrm{OS}$ cells. The 48-h sinomenine treated $\mathrm{U}_{2} \mathrm{OS}$ cells were harvested for immunofluorescence. The cell nucleus was labeled with DAPI (blue), the actin filament was labeled by actin-tracker (green) for cytomembrane location. The target proteins were stained using CXCR4 (bar, $200 \mu \mathrm{m}$ ) and p-STAT3 (bar, $20 \mu \mathrm{m}$ ) antibody, and then incubated with fluorescent secondary antibody (Alexa Fluor 488, red). The images were merged by IPP software. GAPDH was used as internal control. Experiments were repeated three times.

power field). All the H\&E staining results suggested that it was a high-grade malignant tumor. The bone cortex showed serious destruction in the control group, but the condition improved in the sinomenine treatment group. The fast green staining showed the ossein equal to bone cortex and also indicated improvement to the bone destruction by sinomenine treatment (Fig. 9C, fast green staining). TRAP staining was performed to indicate the tumor associated osteoclastogenesis in bone and tumor tissue. The number of osteoclast declined significantly after $150 \mathrm{mg} / \mathrm{kg}$-sinomenine treatment 
A

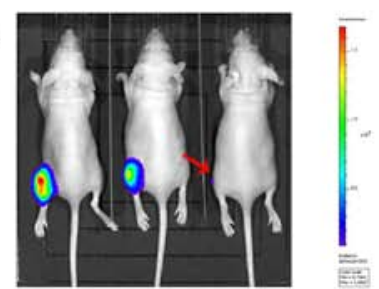

$\mathrm{C}$
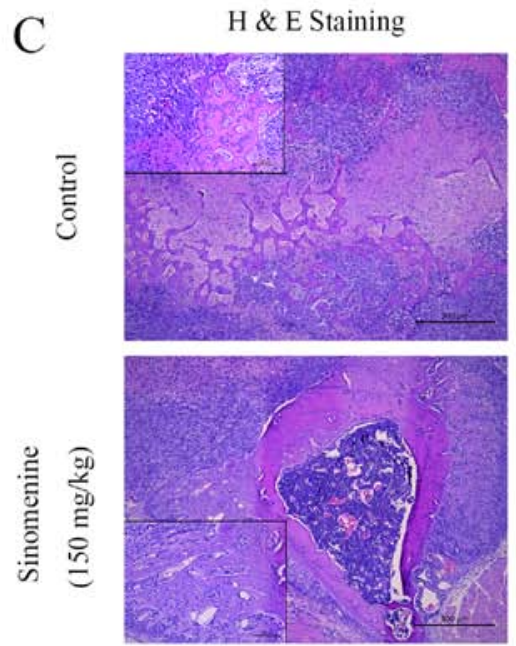

$\mathrm{D}$
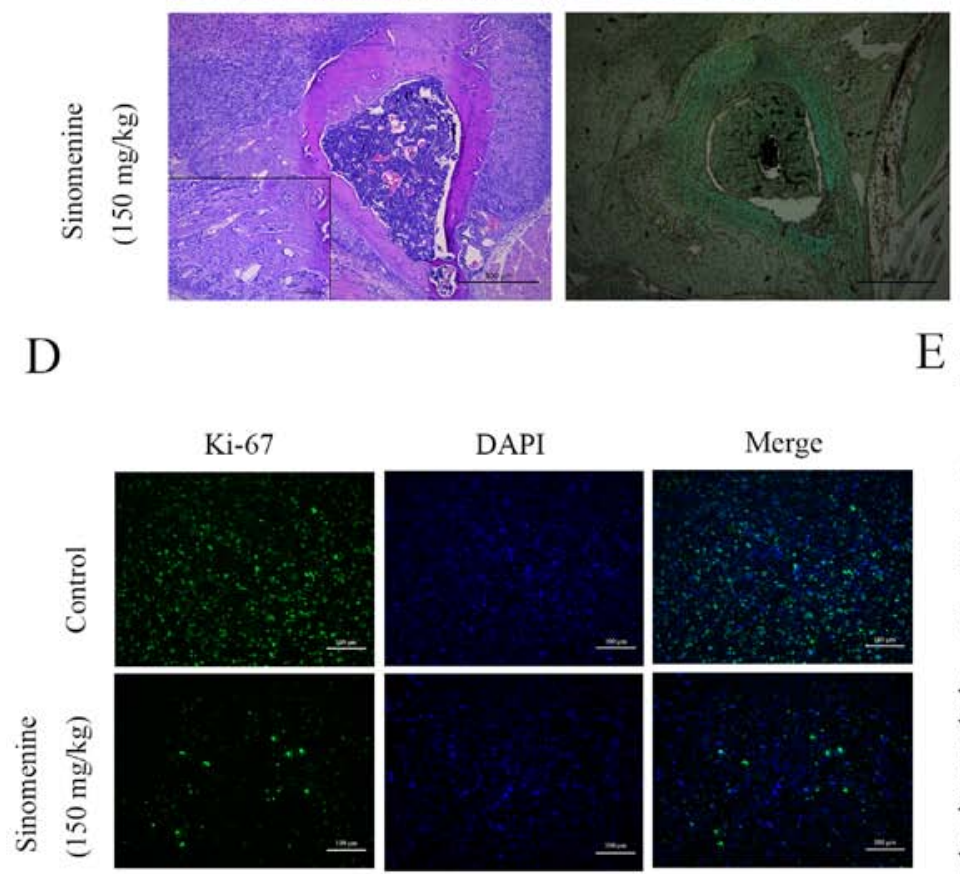

Fast Green Staining
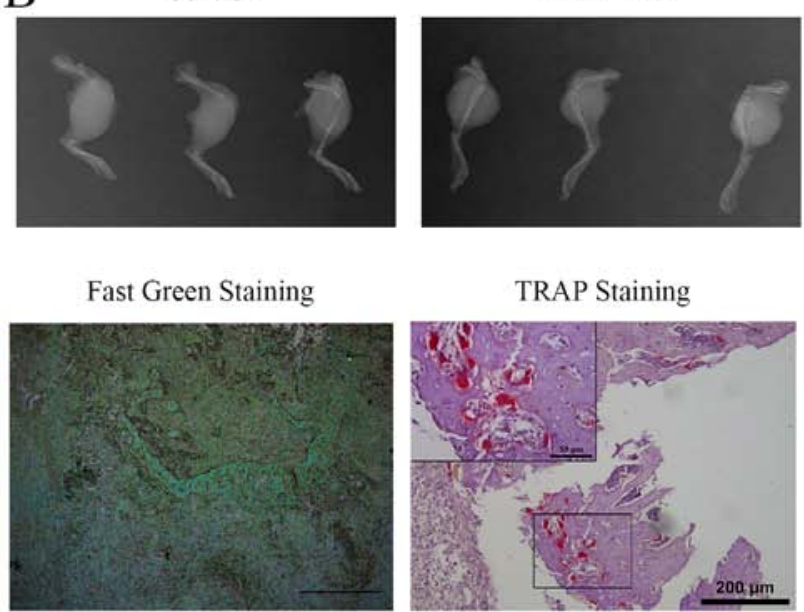

TRAP Staining
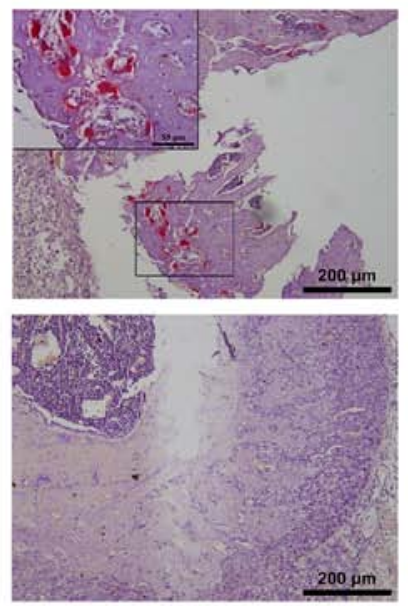

$\mathrm{E}$
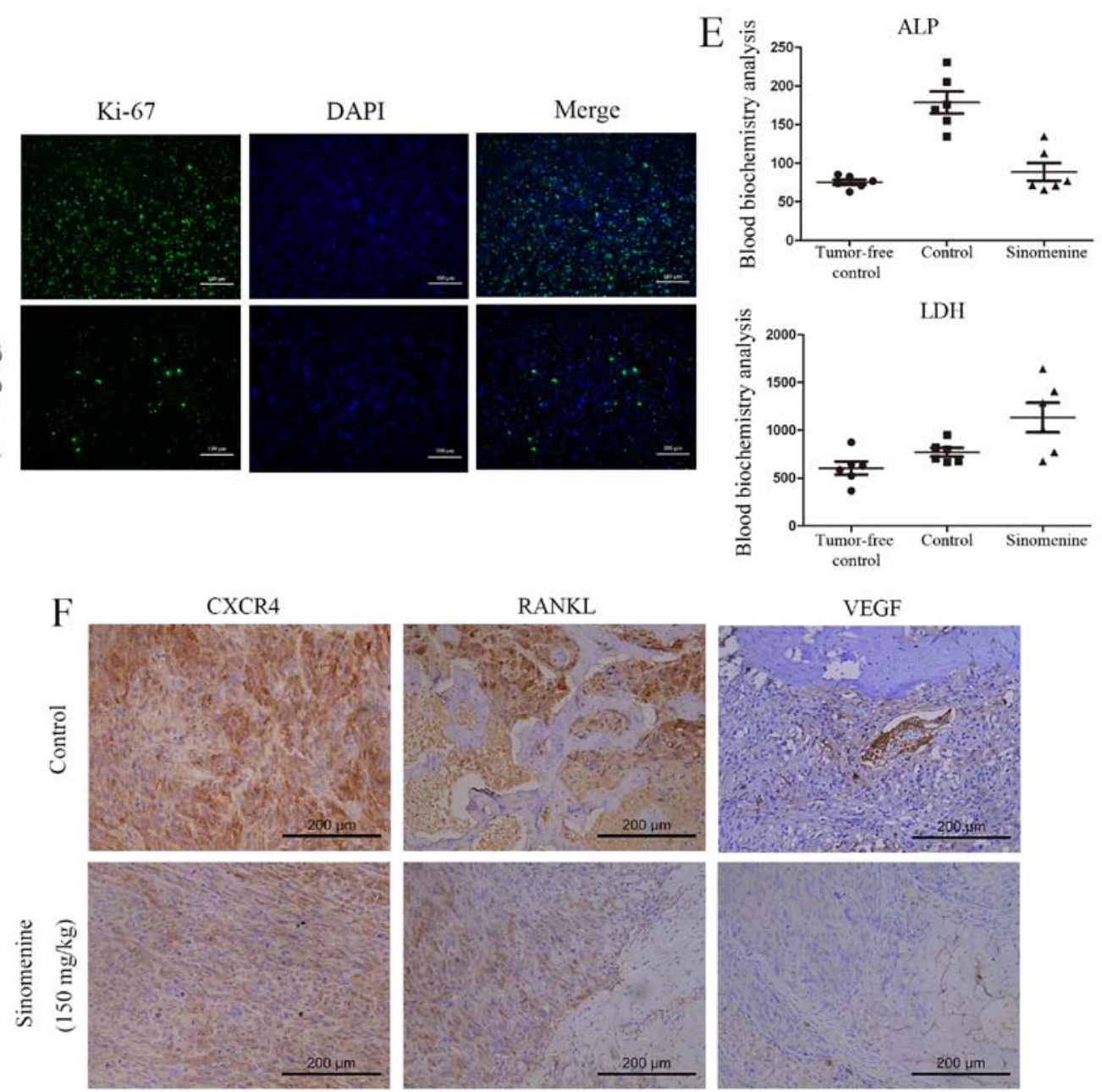

Figure 9. Sinomenine suppresses RANKL mediated osteolysis and regulates the expression of ALP in vivo. HOS-Luc cells were inoculated in the left tibia cavity of BALB/c-nu mice. (A) Intraperitoneal administration of vehicle or sinomenine $(150 \mathrm{mg} / \mathrm{kg})$ daily was started at day 10 after confirming tumor location in tibia cavity and software-simulative cell number by luciferase imaging. The treatment lasted for 14 days, then all mice were sacrificed. (B) The tumor-located left legs were fixed and received X-ray treatment to assess the osteolysis in tibia. (C) The samples were H\&E stained (bar, 50 and $500 \mu \mathrm{m}$ ), fast green staining (bar, $500 \mu \mathrm{m}$ ) and TRAP staining (bar, $200 \mu \mathrm{m}$ ) was used to estimate the tumor development, osteolysis and osteoclast formation. (D) The sample sections received immunofluorescent staining of Ki-67 (green). The nuclear was labeled with DAPI (blue), bar, $100 \mu \mathrm{m}$. The images were merged by IPP software. (E) Blood was drawn from mice before being sacrificed for blood biochemistry examination. The results of ALP and LDH are presented. 
(Fig. 9C, TRAP staining). The results of blood biochemistry examination for ALP and LDH are presented (Fig. 9E).

\section{Discussion}

Osteosarcoma is the most common primary malignant bone tumor. Although the long-term survival reaches $68 \%$, the prognosis of patients with recurrence and metastasis in osteosarcoma is poor $(6,21)$. Innovative pharmaceuticals need further improvement of outcome in osteosarcoma, especially in metastatic management. Sinomenine, traditional Chinese herbal medicine, is known because of its anti-inflammatory effect on arthritis (22-24). Substantial research has reported that sinomenine has antitumor activity in various malignant tumors. Li et al reported that sinomenine induces breast cancer cell death via MAPK signal pathway and reactive oxygen species (ROS) generation (15). Combined chemotherapy with senomenine treatment (25-28) has been revealed to sensitize multidrug-resistant cancer cells in various cancers. Song et al demonstrated that sinomenine inhibited invasion and migration in breast cancer by suppressing NF- $\mathrm{\kappa B}$ activation (17). Furthermore, there are studies suggested that sinomenine inhibits metastasis via suppressing vascularization and osteoclast formation $(29,30)$. Sinomenine has been reported to be anti-neoplasmic by promoting apoptosis in several cancer lines $(28,29)$, but we did not find similar results in our study in osteosarcoma. Nevertheless, significant inhibitory effects were found on proliferation and metastasis via $\mathrm{S}$ phase arrest and the functions in anti-osteolysis, anti-neovascularization, and suppression of the secretion and activation of MMP-2 and MMP-9 through CXCR4-STAT3 pathway in vitro and in vivo.

Unlike previously reported $(13,15)$, we found a significant $S$ phase arrest in the cell cycle, using flow cytometry and protein level western blot analysis. Both the HOS and $\mathrm{U}_{2} \mathrm{OS}$ cells were blocked in $\mathrm{S}$ phase by sinomenine-treatment DNA damage (Fig. 2A-C). The checkpoint kinase Chk2 was activated and phosphorylated for DNA repair which induced downstream phosphorylation of p53 and activation of p21. The function of cyclin A-CDK2 complex was suppressed by $\mathrm{p} 21$ which contributed to block cells from $\mathrm{S}$ phase into G2 phase (Fig. 2D). We did not assess the cycle regulator expression in HOS cell line because of its p53 deficiency. We repeated our experiments and speculate the different results to be due to different cycle regulator expression in the various malignancies.

CXCR4 is capable of directing the trafficking of normal and malignant cells to organs that express high levels of stromal-derived factor-1 (SDF-1), including the lymph nodes, lungs, liver and bone. CXCR4 involvement in metastasis has been suggested in a variety of tumors and its expression in the primary site has been clinically correlated with tumor progression or poor survival in osteosarcoma. It is generally recognized to be associated with metastasis and play an essential role in cell migration and invasion (31-35). Constitutive activation of STAT3 has been found in a wide variety of human tumors. Aberrant STAT3 signaling promotes initiation and progression of human cancers by either inhibiting apoptosis or inducing cell proliferation, angiogenesis, invasion, and metastasis. It has been reported that CXCR4 signaling activates the JAK2/STAT3 pathway in many types of cancers $(36,37)$. To elucidate the signaling pathways underlying sinomenine-mediated responses in osteosarcoma cells, we further investigated the effects of sinomenine on CXCR4 and STAT3 pathways. In this study, we found overexpression of CXCR4 in human primary osteosarcoma. In addition, we explored the role of CXCR4 contributing to cell invasion in $\mathrm{U}_{2} \mathrm{OS}$ cells. Downregulating the CXCR4 by its specific inhibitor plerixafor suppressed the expression of MMP-2 and MMP-9 (Fig. 7B) while inhibited the invasion assessed by Transwell assay (Fig. 7C). The inhibitory effect induced by CXCR4 downregulation could be blocked by CXCR4 activator SDF-1. Our results were compared with sinomenine treatment group (Fig. 7B and C). The sinomenine decreased the expression of CXCR4 and MMP-2 and -9 in $\mathrm{U}_{2} \mathrm{OS}$ and the inhibitory effect was reversed by using SDF-1 in the treatment group. There results suggested the essential role of CXCR4 in contributing to invasion and as acting site in sinomenine treatment in osteosarcoma cells. The western blot analysis and immunofluorescence staining confirmed our viewpoint (Fig. 8A and I). The sinomenine treatment indeed suppressed the expression of CXCR4 and its downstream STAT3 phosphorylation and the MMP-2 and MMP-9. Further study revealed that SDF-1 activated sinomenine-inhibited CXCR4, which had a positive correlation to RANKL, VEGF and MMP-2 and -9 expression and in Transwell assay. In addition, our results showed that sinomenine treatment inhibited tube formation ability of HUVECs. The capacity of $\mathrm{U}_{2} \mathrm{OS}$ cells to form tube-like structures was also surppressed by sinomenine. Thus, strong evidence was provided that sinomenine inhibited invasion and metastasis mainly through CXCR4-STAT3 pathway and then regulated the expression of MMP-2, MMP-9, RANKL and VEGF downstream in osteosarcoma.

Osteoclasts are multinucleated cells of hematopoietic origin and are responsible for the degradation of mineralized bone matrix. RANKL is a key cytokine for osteoclast differentiation, survival and function (38). Activation of the NF- $\kappa \mathrm{B}$ pathway is a key factor in RANKL-induced osteoclast differentiation. Blocking RANKL and its associated signaling cascades is a vital step for successful treatment of some osteoclast-related diseases. Our results showed that sinomenine inhibited the expression of RANKL and phospho-NF- $\mathrm{kB}$. In addition, an orthotopic mouse model of osteosarcoma was used to investigate the treatment effects of sinomenine in vivo. In X-ray examination, bone destruction improved in sinomenine treated group comparing with the control group (Fig. 9B). H\&E staining and fast green staining also displayed that bone cortices were destructed more seriously in the control group (Fig. 9C). TRAP staining was performed to examine the tumor-associated osteoclastogenesis in bone and tumor tissue, showing that the number of osteoclasts declined significantly after sinomenine treatment. The in vivo results further confirmed sinomenine as a potent suppressor of osteoclast formation and bone destruction and resorption.

The osteogenic marker ALP is highly expressed inside normal bone and osteosarcoma cells. The serum ALP level increases with bone destruction because the ALP is released into serum from bone cells. Therefore, generally the high level 
of ALP is considered to be associated with osteolysis and disease progress which indicates a poor prognosis in clinic. Thus, ALP is adopted as clinically meaningful marker in diagnosis and predicting prognosis in osteosarcoma $(39,40)$. Serum LDH are also known to reflect the tumor burden and associated with poor prognosis (41). Decrease of ALP or LDH levels may be a symptom of a positive reaction to treatment. In our study, the levels of serum ALP increased significantly in tumor group compared with tumor-free group, and decreased markedly after sinomenine treatment, which reflect positive treatment effects of sinomenine. However, in evaluation of serum LDH, we did not observe this tendency. Contrarily, the LDH level increased in the treatment group. This might be due to the hepatic impairment induced by sinomenine. Combined with TRAP, H\&E, and X-ray examination, we have reason to believe that sinomenine-treatment restraints bone destruction and osteolysis in osteosarcoma through inhibiting RANKL-NF- $\kappa \mathrm{B}$ expression and tumor-associated osteoclast activation. The immunohistochemistry confirmed that sinomenine downregulated the RANKL and VEGF expression by inhibiting CXCR4 in vivo.

There are still deficiencies in our experiment. We only verified the CXCR4-STAT3 pathway in $\mathrm{U}_{2} \mathrm{OS}$ cells, but not in HOS cells considering its P53 gene loss and atypical signal regulation in vitro. It might be better to complete it in HOS cells. The orthotopic tumor histology sections were made in tibia transection not in shaft position. It most probably missed the typical osteolysis area in tibia cortex. It would be better to make the sections in tibia axle. We found the mouse blood biochemistry of LDH increased after sinomenine treatment. We speculated it might be induced by drug hepatotoxicity. We did not harvest the mice liver for further examination, and we did not meet the inhibitory effect on tumor growth in osteosarcoma through sinomenine treatment. Tumor cells seeded in marrow cavity also developed in tibia around soft tissues in treatment group even if under low bone destruction and osteolysis condition. It indicates a complicated progress in osteosarcoma development, the bone cortex is destroyed not only by tumor-associated osteoclastogenesis, but also direct aggression by osteosarcoma cells. There might be a better outcome if higher doses were given or sinomenine combined with other agents in osteosarcoma therapy.

In conclusion, this study is the first to demonstrate that sinomenine can effectively inhibit the proliferation by inducing $\mathrm{S}$ phase arrest, and suppresses metastasis in osteosarcoma via downregulating CXCR4-STAT3 signal pathway and then restraining the RANKL-mediated bone destruction stimulated by osteoclastogenesis and VEGF-related neovascularization in osteosarcoma. The above results suggest that sinomenine may be a promising adjuvant agent for metastatic control in osteosarcoma.

\section{Acknowledgements}

This study was supported in part by grants from the National Natural Science Foundation of China (no. 81172547). We thank Dr Y.-Q. Xie (Department of Clinical Research Centre, Zhejiang, China) for the gift of HUVEC.

\section{References}

1. Quaye AA, Raskin KA, Ecker JL and Leffert LR: Management of a parturient with high-grade osteosarcoma of the proximal femur: A multidisciplinary approach. Int J Obstet Anesth 19: 340-342, 2010.

2. Raymond AK and Jaffe N: Osteosarcoma multidisciplinary approach to the management from the pathologist's perspective. Cancer Treat Res 152: 63-84, 2009.

3. Weiss A, Gill J, Goldberg J, Lagmay J, Spraker-Perlman H, Venkatramani R and Reed D: Advances in therapy for pediatric sarcomas. Curr Oncol Rep 16: 395, 2014.

4. Kudawara I, Aoki Y, Ueda T, Araki N, Naka N, Nakanishi H, Matsumine A, Ieguchi M, Mori S, Myoui A, et al: Neoadjuvant and adjuvant chemotherapy with high-dose ifosfamide, doxorubicin, cisplatin and high-dose methotrexate in non-metastatic osteosarcoma of the extremities: A phase II trial in Japan. J Chemother 25: 41-48, 2013.

5. Kager L, Zoubek A, Pötschger U, Kastner U, Flege S, KempfBielack B, Branscheid D, Kotz R, Salzer-Kuntschik M, Winkelmann W, et al; Cooperative German-Austrian-Swiss Osteosarcoma Study Group: Primary metastatic osteosarcoma: Presentation and outcome of patients treated on neoadjuvant Cooperative Osteosarcoma Study Group protocols. J Clin Oncol 21: 2011-2018, 2003

6. Kempf-Bielack B, Bielack SS, Jürgens H, Branscheid D, Berdel WE, Exner GU, Göbel U, Helmke K, Jundt G, Kabisch H, et al: Osteosarcoma relapse after combined modality therapy: An analysis of unselected patients in the Cooperative Osteosarcoma Study Group (COSS). J Clin Oncol 23: 559-568, 2005.

7. Birkedal-Hansen H, Moore WG, Bodden MK, Windsor LJ, Birkedal-Hansen B, DeCarlo A and Engler JA: Matrix metalloproteinases: A review. Crit Rev Oral Biol Med 4: 197-250, 1993.

8. Nabeshima K, Iwasaki H, Koga K, Hojo H, Suzumiya J and Kikuchi M: Emmprin (basigin/CD147): Matrix metalloproteinase modulator and multifunctional cell recognition molecule that plays a critical role in cancer progression. Pathol Int 56: 359-367, 2006

9. Clézardin P: The role of RANK/RANKL/osteoprotegerin (OPG) triad in cancer-induced bone diseases: Physiopathology and clinical implications. Bull Cancer 98: 837-846, 2011 (In French).

10. Yamasaki H: Pharmacology of sinomenine, an anti-rheumatic alkaloid from Sinomenium acutum. Acta Med Okayama 30: 1-20, 1976.

11. Zhou L, Luan H, Liu Q, Jiang T, Liang H, Dong X and Shang H: Activation of PI3K/Akt and ERK signaling pathways antagonized sinomenine-induced lung cancer cell apoptosis. Mol Med Rep 5: 1256-1260, 2012.

12. Li XJ, Yue PY, Ha WY, Wong DY, Tin MM, Wang PX, Wong RN and Liu L: Effect of sinomenine on gene expression of the IL-1 beta-activated human synovial sarcoma. Life Sci 79: 665-673, 2006.

13. Lu XL, Zeng J, Chen YL, He PM, Wen MX, Ren MD, Hu YN, Lu GF and He S: Sinomenine hydrochloride inhibits human hepatocellular carcinoma cell growth in vitro and in vivo: Involvement of cell cycle arrest and apoptosis induction. Int $\mathbf{J}$ Oncol 42: 229-238, 2013

14. Lv Y, Li C, Li S and Hao Z: Sinomenine inhibits proliferation of SGC-7901 gastric adenocarcinoma cells via suppression of cyclooxygenase-2 expression. Oncol Lett 2: 741-745, 2011.

15. Li X, Wang K, Ren Y, Zhang L, Tang XJ, Zhang HM, Zhao CQ, Liu PJ, Zhang JM and He JJ: MAPK signaling mediates sinomenine hydrochloride-induced human breast cancer cell death via both reactive oxygen species-dependent and -independent pathways: An in vitro and in vivo study. Cell Death Dis 5: e1356, 2014.

16. Ou YQ, Chen LH, Li XJ, Lin ZB and Li WD: Sinomenine influences capacity for invasion and migration in activated human monocytic THP-1 cells by inhibiting the expression of MMP-2, MMP-9, and CD147. Acta Pharmacol Sin 30: 435-441, 2009.

17. Song L, Liu D, Zhao Y, He J, Kang H, Dai Z, Wang X, Zhang S and Zan Y: Sinomenine inhibits breast cancer cell invasion and migration by suppressing NF- $\kappa \mathrm{B}$ activation mediated by IL-4/ miR-324-5p/CUEDC2 axis. Biochem Biophys Res Commun 464: 705-710, 2015.

18. Zhou Q, Zhu Y, Deng Z, Long H, Zhang S and Chen X: VEGF and EMMPRIN expression correlates with survival of patients with osteosarcoma. Surg Oncol 20: 13-19, 2011. 
19. Benayoun Y, Petellat F, Leclerc O, et al: Current treatments for corneal neovascularization. J Fr Ophtalmol 38: 996-1008, 2015.

20. Yan L, Zucker S and Toole BP: Roles of the multifunctional glycoprotein, emmprin (basigin; CD147), in tumour progression. Thromb Haemost 93: 199-204, 2005.

21. Meyers PA, Schwartz CL, Krailo M, Kleinerman ES, Betcher D, Bernstein ML, Conrad E, Ferguson W, Gebhardt M, Goorin AM, et al: Osteosarcoma: A randomized, prospective trial of the addition of ifosfamide and/or muramyl tripeptide to cisplatin, doxorubicin, and high-dose methotrexate. J Clin Oncol 23: 2004-2011, 2005.

22. Chen DP, Wong CK, Leung PC, Fung KP, Lau CB, Lau CP, Li EK, Tam LS and Lam CW: Anti-inflammatory activities of Chinese herbal medicine sinomenine and Liang Miao San on tumor necrosis factor- $\alpha$-activated human fibroblast-like synoviocytes in rheumatoid arthritis. J Ethnopharmacol 137: 457-468, 2011.

23. Qian L, Xu Z, Zhang W, Wilson B, Hong JS and Flood PM: Sinomenine, a natural dextrorotatory morphinan analog, is anti-inflammatory and neuroprotective through inhibition of microglial NADPH oxidase. J Neuroinflammation 4: 23, 2007.

24. Tang Q, Luo J, Zhu Q, Li Y and Yin S: Synthesis and antiinflammatory activities investigation of sinomenine derivatives on ring C. Nat Prod Res 20: 1015-1023, 2006.

25. Liu Z, Duan ZJ, Chang JY, Zhang ZF, Chu R, Li YL, Dai KH, Mo GQ and Chang QY: Sinomenine sensitizes multidrug-resistant colon cancer cells (Caco-2) to doxorubicin by downregulation of MDR-1 expression. PLoS One 9: e98560, 2014.

26. Liao F, Yang Z, Lu X, Guo X and Dong W: Sinomenine sensitizes gastric cancer cells to 5-fluorouracil in vitro and in vivo. Oncol Lett 6: 1604-1610, 2013.

27. Chen Y, Zhang L, Lu X, Wu K, Zeng J, Gao Y, Shi Q, Wang X, Chang LS and He D: Sinomenine reverses multidrug resistance in bladder cancer cells via P-glycoprotein-dependent and independent manners. Pharmazie 69: 48-54, 2014.

28. Zhang JX, Yang ZR, Wu DD, Song J, Guo XF, Wang J and Dong WG: Suppressive effect of sinomenine combined with 5 -fluorouracil on colon carcinoma cell growth. Asian Pac J Cancer Prev 15: 6737-6743, 2014.

29. Zhang H, Ren Y, Tang X, Wang K, Liu Y, Zhang L, Li X, Liu P, Zhao $\mathrm{C}$ and $\mathrm{He} \mathrm{J}$ : Vascular normalization induced by sinomenine hydrochloride results in suppressed mammary tumor growth and metastasis. Sci Rep 5: 8888, 2015.

30. Li X, He L, Hu Y, Duan H, Li X, Tan S, Zou M, Gu C, Zeng X, $\mathrm{Yu} \mathrm{L}$, et al: Sinomenine suppresses osteoclast formation and Mycobacterium tuberculosis $\mathrm{H} 37 \mathrm{Ra}$-induced bone loss by modulating RANKL signaling pathways. PLoS One 8: e74274, 2013.
31. Ruffini PA, Morandi P, Cabioglu N, Altundag K and Cristofanilli M: Manipulating the chemokine-chemokine receptor network to treat cancer. Cancer 109: 2392-2404, 2007.

32. Micucci C, Matacchione G, Valli D, Orciari S and Catalano A: HIF $2 \alpha$ is involved in the expansion of CXCR4-positive cancer stem-like cells in renal cell carcinoma. Br J Cancer 113: 1178-1185, 2015.

33. Gu JY, Shi HF, Gao XL, Ma QQ and Zhang B: Effect of CXCR4 pretreated with ultrasound-exposed microbubbles on accelerating homing of bone marrow mesenchymal stem cells to ischemic myocardium in AMI rats. Asian Pac J Trop Med 8: 766-771, 2015.

34. Sand LG, Scotlandi K, Berghuis D, Snaar-Jagalska BE, Picci P, Schmidt T, Szuhai K and Hogendoorn PC: CXCL14, CXCR7 expression and CXCR4 splice variant ratio associate with survival and metastases in Ewing sarcoma patients. Eur J Cancer 51: 2624-2633, 2015.

35. Han AR, Lee JY, Kim HJ, Min WS, Park G and Kim SH: A CXCR4 antagonist leads to tumor suppression by activation of immune cells in a leukemia-induced microenvironment. Oncol Rep 34: 2880-2888, 2015.

36. Liu X, Xiao Q, Bai X, Yu Z, Sun M, Zhao H, Mi X, Wang E, Yao W, Jin F, et al: Activation of STAT3 is involved in malignancy mediated by CXCL12-CXCR4 signaling in human breast cancer. Oncol Rep 32: 2760-2768, 2014.

37. Shen HB, Gu ZQ, Jian K and Qi J: CXCR4-mediated Stat3 activation is essential for CXCL12-induced cell invasion in bladder cancer. Tumour Biol 34: 1839-1845, 2013.

38. Hanada R, Hanada T, Sigl V, Schramek D and Penninger JM: RANKL/RANK - beyond bones. J Mol Med (Berl) 89: 647-656, 2011.

39. Li C, Shi X, Zhou G, Liu X, Wu S and Zhao J: The canonical Wnt-beta-catenin pathway in development and chemotherapy of osteosarcoma. Front Biosci (Landmark Ed) 18: 1384-1391, 2013.

40. Moore AS, Dernell WS, Ogilvie GK, Kristal O, Elmslie R, Kitchell B, Susaneck S, Rosenthal R, Klein MK, Obradovich J, et al: Doxorubicin and BAY 12-9566 for the treatment of osteosarcoma in dogs: A randomized, double-blind, placebocontrolled study. J Vet Intern Med 21: 783-790, 2007.

41. Durnali A, Alkis N, Cangur S, Yukruk FA, Inal A, Tokluoglu S, Seker MM, Bal O, Akman T, Inanc M, et al: Prognostic factors for teenage and adult patients with high-grade osteosarcoma: An analysis of 240 patients. Med Oncol 30: 624, 2013. 